\title{
Sistemas de captación de agua en la prehistoria de Menorca: la cisterna del Círculo 6 de Torre d'en Galmés
}

\author{
Carlos de Salort Giménez (1), Borja Corral Garcíaa (1), Carmen Lara Astiz ${ }^{(1,2,3)}$, \\ Joaquín Pons Machado ${ }^{(1,2,3)}$, Agustí Rodríguez Florit ${ }^{(2,4)}$ y Pedro Robledo Ardila ${ }^{(5)}$ \\ (1) Amics del Museu de Menorca, Av. Doctor Guàrdia s/n, 07701 Maó \\ carlosdesalort@outlook.com \\ corralgarciaborja@gmail.com \\ (2) Institut Menorquí d'Estudis, Camí des Castell 28, 07702 Maó \\ (3) Grup de Recerques Arqueològiques de la Mediterrània i el Pròxim Orient (GRAMPO,UAB), \\ Mòdul de Recerca A, 08193 Bellaterra \\ quimmentxu@ hotmail.com \\ (4) Geoservei, projectes i gestió ambiental, C. Himàlaia 37, 07703 Maó \\ a.rodriguez@geoservei.com \\ (5) Instituto Geológico y Minero de España. UnidadTerritorial de les Illes Balears C/ de Felicià Fuster, 7, \\ 07006 Palma de Mallorca \\ pa.robledo@igme.es
}

\begin{abstract}
RESUMEN
Los asentamientos humanos en la prehistoria y en la historia de Menorca están ligados a la facilidad para obtener recursos hídricos. Por este motivo, la mayor parte de comunidades pretalayóticas (2300-1200 ANE) y talayóticas (1200-123 ANE) se concentran en la plataforma carbonática del Migjorn, formadas por calizas y calcarenitas miocenas que abarca la mitad sur de la isla. Se han documentado diferentes estructuras de captación de agua del subsuelo y sistemas de captación y almacenamiento de aguas superficiales: pozos, sistemas de canalización, decantación y almacenaje en cisternas, charcas y cubetas artificiales o naturales. En el marco de un proyecto de excavación de espacios domésticos en el poblado talayótico de Torre d'en Galmés, en 2016, se excavó una gran cisterna prehistórica amortizada a partir de los siglos VII y VIII de nuestra era. Este hallazgo permite valorar las distintas posibilidades de captación del recurso hídrico en el poblado, relacionar la estructura con las características arquitectónicas conocidas de las casas del periodo (siglos III -II ANE) y con otras estructuras prehistóricas e históricas similares en la isla.
\end{abstract}

Palabras clave: captación de agua, cultura talayótica, depósito, edad del Hierro.

\section{Water collection systems in the prehistory of Menorca: the Circle 6 cistern at Torre d'en Galmés}

\begin{abstract}
Human settlements during prehistoric and historic times on the island of Menorca have been linked to the easy access to water supplies. Therefore, most of the pre-Talayotic (2300-1200 BCE) and Talayotic (1200-123 BCE) communities are found concentrated along the Migjorn Miocene platform composed of limestone and calcarenite that covers the southern half of the island. Several structures have been documented that relate to underground water collection and rainwater harvesting and storage, i.e. wells, systems for canalization, filtering and storing water in cisterns, puddles and natural or artificial storage pits. As part of an archaeological project to study domestic spaces in the Talayotic settlement of Torre d'en Galmés, a large prehistoric cistern -fallen into disuse after the 7th and 8th century CE- was excavated in 2016. This find has allowed us to evaluate the several options for water collection used in the settlement, and to relate this structure to the known architectural characteristics of the houses during this period - 3rd and 2nd centuries BCE- and to other prehistoric and historic structures on the island of Menorca.
\end{abstract}

Keywords: deposit, Iron Age, Talayotic Culture, water collection. 


\section{Introducción}

El agua es un elemento fundamental para la vida. Plantas, animales y personas dependemos de ella para poder subsistir. Por lo tanto, su obtención y almacenamiento siempre ha sido una cuestión prioritaria para las comunidades humanas y las soluciones que se han ido adoptando son muy diversas en las distintas regiones del planeta.

La isla de Menorca no es una excepción. Esta pequeña isla del Mediterráneo se encuentra en el Archipiélago Balear y su reducida extensión (700km2), junto a un relieve poco desarrollado, impiden que se hayan formado cursos de agua superficiales extensos y permanentes. No obstante, gracias al subsuelo de una parte importante de la isla, formado por rocas calizas fisuradas y porosas, el agua de lluvia se infiltra hasta llegar a un nivel donde el terreno está totalmente saturado de agua, formando acuíferos de gran importancia. Los barrancos, que generalmente van de norte a sur de la isla, se encuentran encajados en la envolvente de la superficie topográfica. En algunos casos, el nivel freático del acuífero intersecta dicha superficie, dando lugar a surgencias de diversa entidad. Esto también sucede, por ejemplo, en los torrentes que drenan los barrancos que, muchas veces, se alimentan de aguas subterráneas, o al final de su recorrido, donde se originan fuentes, como es el caso de Calescoves y otras zonas de esta parte de la isla (Trilla, 1980). La explotación de las aguas subterráneas por parte de las diferentes comunidades dependerá de la permeabilidad del terreno y de la profundidad del nivel freático local, lo cual puede suponer un ingenio y un esfuerzo considerables. La climatología es la propia del clima mediterráneo: templada en invierno y con veranos secos, concentrándose los periodos de precipitaciones durante el otoño y la primavera. La proximidad del mar suaviza las temperaturas debido a su efecto termorregulador. Cabe mencionar el viento, en especial el viento de norte, muy conocido en Menorca como la tramontana. La realidad pluviométrica destaca por su irregularidad; la media anual en el período 19712000 y en la zona sur de Menorca osciló entorno a los 450-650 mm. Hay marcadas diferencias entre un año y otro, y dentro de un mismo año, episodios de fuertes lluvias, incluso torrenciales, y largos periodos, que pueden ser muy largos, sin lluvia (Jansà, 2004).

Por todos estos motivos, en la arquitectura tradicional de la isla es evidente la preocupación por derivar, canalizar y almacenar directamente el agua de la lluvia. En consecuencia, desde el momento inicial de la ocupación humana de la isla, alrededor del final del tercer milenio ANE, se pueden ver tanto, estructuras para captar aguas subterráneas como superficiales.

La geología tiene un papel determinante en la dinámica de los asentamientos humanos y la gestión del territorio menorquín. Se distinguen claramente dos zonas que dividen el territorio prácticamente en dos mitades (Fig. 1ab). La región de Tramuntana, al nor-
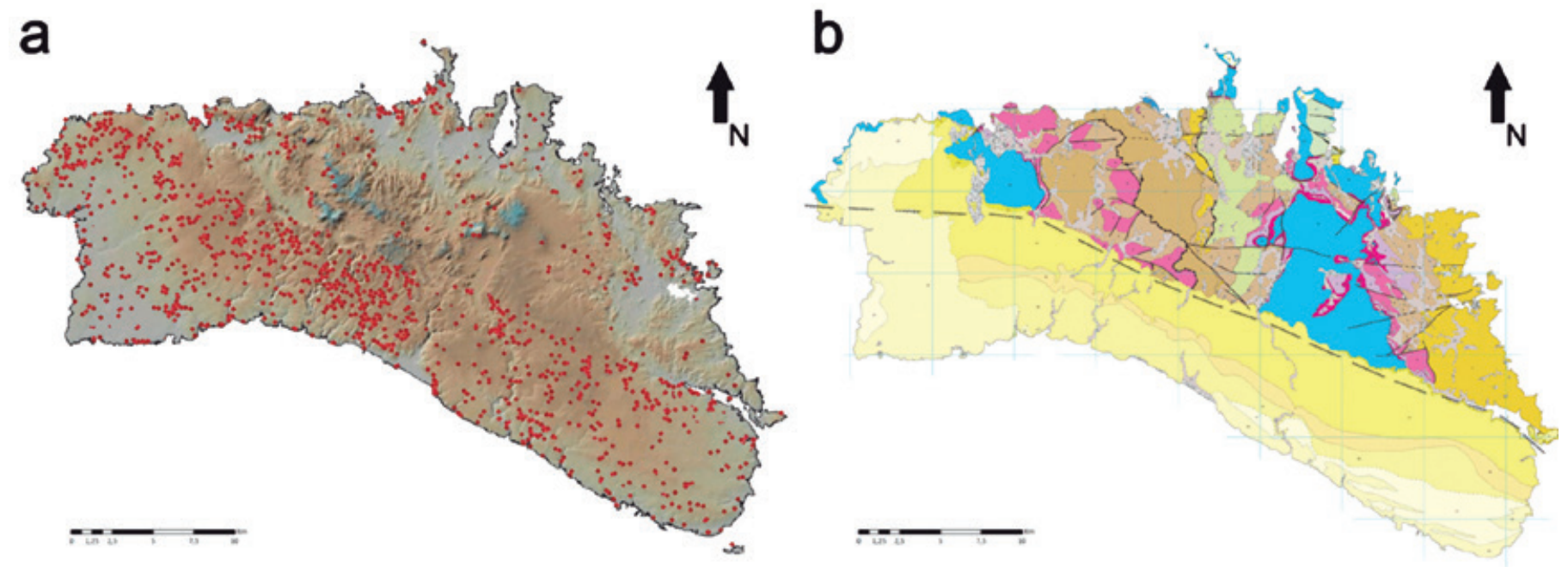

Figura 1. (a) Distribución de los restos arqueológicos en la isla (Servei de Patrimoni Històric- Consell Insular de Menorca). (b) Mapa geológico: en la mitad norte los terrenos son de la era paleozoica y mesozoica, mientras que en la mitad sur los terrenos pertenecen a la era cenozoica y constituyen una extensa plataforma calcárea mucho más favorable para el hábitat humano (Instituto Geológico y Minero de España, 2015).

Figure 1. (a) Distribution of archaeological remains on the island (Servei de Patrimoni Històric - Consell Insular de Menorca). (b) Geological map of the island: Materials on the northern part of the island come from the Palaeozoic and Mesozoic; on the other hand, the south area is mainly made up of Cenozoic era rocks that constitute an extensive limestone platform more suitable for human habitation (Instituto Geológico y Minero de España, 2015). 

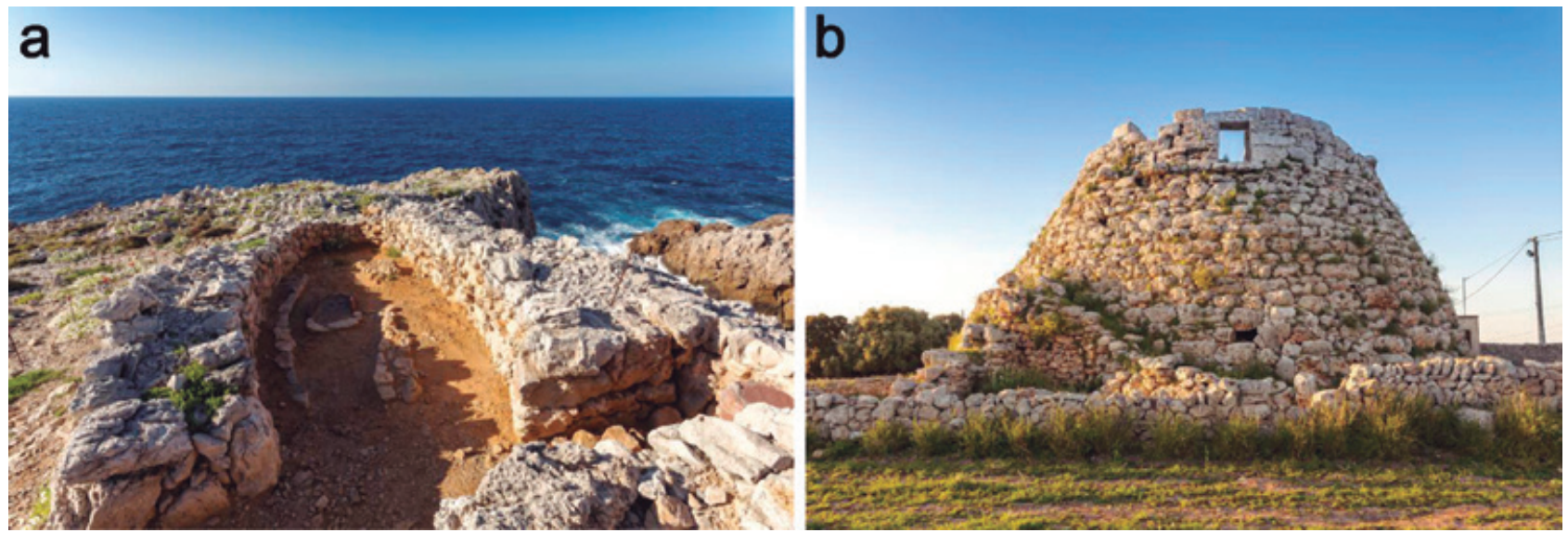

Figura 2. (a) Naveta de habitación del cabo costero de Cala Morell en el municipio de Ciudadela (Menorca Talayótica - CIM). (b) Talayot de Torelló en Maó (Menorca Talayótica- CIM).

Figure 2. (a) Dwelling naveta on the coastal headland of Cala Morell in the municipality of Ciutadella (Menorca Talayótica - CIM). Talayot of Torelló in Maó (Menorca Talayótica - CIM).

te, que está formada por materiales paleozoicos (correspondientes a una serie turbidítica constituida por lutitas, areniscas y conglomerados, con esporádicas intercalaciones de calizas y radiolaritas sedimentadas entre el límite Silúrico-Devónico y el Carbonífero inferior y areniscas y pelitas rojas del Pérmico), materiales del Mesozoico (areniscas, calizas, margas y dolomías desde el Triásico inferior al Cretácico inferior) y rocas del Oligoceno superior - Mioceno inferior. En general, son materiales poco permeables, por lo que las acumulaciones naturales de agua en la superficie del terreno son muy frecuentes en cuanto llueve. Por toda la zona norte se observan marismas y charcas temporales, creando unas condiciones de vida relativamente insalubres por la presencia de agua estancada que tienen el reflejo en una baja densidad de ocupación en época prehistórica e histórica.

La zona sur, en cambio, está formada por rocas del Mioceno superior (Tortoniense a Messiniense) con una disposición subhorizontal y correspondientes básicamente a facies litorales de plataforma marina (rampa carbonatada y arrecifes). Es una plataforma surcada por grandes barrancos que van desde el centro de la isla hacia la costa, creando unos espacios muy protegidos de las condiciones atmosféricas y con una sedimentación favorable para ser utilizadas como zonas de cultivo y pasto para el ganado. Por este motivo, las condiciones de vida en esta parte de la isla son mucho más benévolas y la ocupación humana es más abundante que la de la zona norte. De hecho, el mismo terreno ofrece el material ideal para la construcción de los poblados de los habitantes prehistóricos de la isla: la piedra caliza.

Desde el punto de vista histórico, podemos dividir la prehistoria de Menorca en dos grandes períodos. La primera ocupación de la isla se conoce como pretalayótico o naviforme y se sitúa cronológicamente entre el 2.200 y el 1.200 ANE, aproximadamente. Corresponde a un poblamiento disperso, en pequeños poblados de cabañas de forma alargada, construidas en piedra, que reciben el nombre de navetas (Fig. 2a). Su fuente de subsistencia se basaría en una economía agrícola-ganadera.

El segundo período de la prehistoria de Menorca es el que conocemos como cultura Talayótica (denominación proveniente de la palabra talayot, derivada de atalaya). Se extiende desde el 1.200 hasta el 123 ANE, cuando la isla se incorpora al mundo romano. En esa fase, el poblamiento de la isla se dispara, como se puede apreciar por la gran abundancia de poblados talayóticos. Según algunos investigadores es probable que, inmediatamente después de la conquista romana, se alcanzaran los 30.000 hab (De Cet et al., 2017). La sociedad también se hace más compleja, ya que en el interior de los poblados encontramos diferentes tipos de edificios: talayots (grandes torres de piedra de forma cónica truncada), casas, recintos cubiertos (posibles almacenes), recintos de taula (con función religiosa), murallas y sistemas de recogida de agua (Fig. 2b). La base económica continuará siendo la agricultura y la ganadería.

\section{Marco hidrogeológico}

Las características estructurales y estratigráficas de Menorca condicionan la distribución espacial de sus acuíferos y su compartimentación. El Plan Hidrológico de les Illes Balears (PHIB, 2019) define seis masas de agua subterránea (MAS) en Menorca, que son herederas de tres unidades hidrogeológicas (U.H.) definidas 


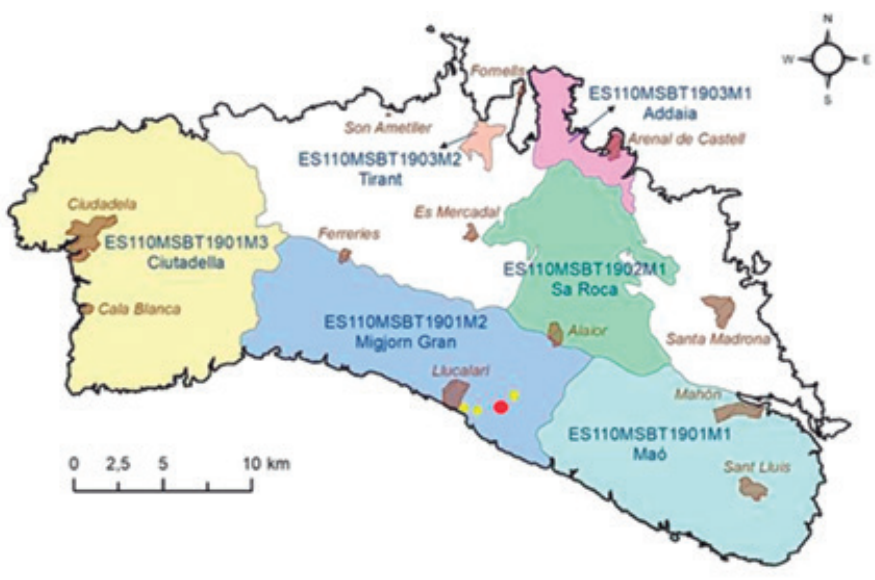

Figura 3. Masas de Agua Subterránea definidas en la isla de Menorca. Las masas con codificación 1901 corresponden a la U.H. Migjorn, la 1902 a la U.H. Albaida y las que muestran 1903 a la U.H. Fornells.

Figure 3. Underground water masses defined on the island of Menorca. The masses identified with unit code 1901 correspond to the hydrogeologic unit Migjorn, with code 1902 to the H.G.U. Albaida and the ones with unit code 1903 to the H.G.U. Fornells.

con anterioridad, de las cuales dos se localizan en el norte (U.H. Fornells y U.H. Albaida) y la tercera constituye toda la región miocena de la isla, junto a unos afloramientos de calizas del Lías localizados al este de Ciutadella (U.H. Migjorn) (Fig. 3).

Tal y como se ha indicado, esta división geológica tuvo una gran influencia en la distribución de los asentamientos humanos prehistóricos, ubicándose estos especialmente en la superficie ocupada por la U.H. Migjorn, con la excepción de los afloramientos del Lías. De hecho, es importante señalar que a diferencia de la U.H. Fornells, constituida preferentemente por las rocas poco permeables mencionadas anteriormente, la U.H. Albaida está formada esencialmente por rocas duras carbonatadas y permeables del Lías. La baja densidad de asentamientos en la zona de Albaida, manifiesta que, en este caso, el acceso al agua no fue determinante para su ocupación.

En el Migjorn de Menorca, los mapas de piezometría indican un flujo radial del agua desde el centro de la isla hacia el sur, este y oeste. Se debe relacionar este hecho a que las máximas cotas topográficas se encuentran en las zonas centrales de la isla y a que la U.H. Migjorn corresponde a un acuífero libre.

La diferencia de cota de los niveles piezométricos según los sectores de esta U.H. es muy significativa. En la zona central del Migjorn la pendiente es muy pronunciada, mientras que al este y especialmente al oeste, en Ciutadella, la pendiente que describe las isopiezas es mucho más tendida. Este hecho se está relacionado por una parte con las diferencias de permeabilidad de sus rocas y por otra parte con paleo- relieve. Los materiales menos permeables de la zona central, impiden una circulación rápida de las aguas subterráneas y provocan un gradiente más elevado que al este y oeste, donde se encuentran las rocas más permeables. A su vez, especialmente en la zona central del Migjorn, las variaciones de permeabilidad implican que no sea extraño localizar pilancones o cubetas naturales, pero en ocasiones ahondadas antropicamente, y que son impermeabilizadas mediante procesos diagenéticos naturales o por la colmatación con sedimento arcilloso de procedencia externa (Obrador, 2016).

Las diferencias de permeabilidad, tienen consecuencias a nivel cuantitativo, pero también de calidad de las aguas subterráneas lo que ha sido uno de los criterios para la división de la antigua U.H. Migjorn en tres masas de agua subterránea. Desde los años 80 del siglo pasado, la calidad del agua subterránea ha sufrido importantes problemas de contaminación en las MAS del este y del oeste. Estos problemas están asociados a la presencia de nitratos por un uso excesivo de fertilizantes nitrogenados y de cloruros por el intenso bombeo que desencadena procesos de intrusión agua marina en las zonas más próximas al litoral. De hecho, entre 1980 y 2005 el descenso del nivel piezométrico regional del acuífero, en algunos sectores de su parte central, fue de entre 30 y $40 \mathrm{~m}$ (Giménez et al., 2004). Esta situación desencadenó la desaparición de numerosas fuentes en los barrancos que surcan esta zona, que muy probablemente fueron aprovechadas en época prehistórica.

\section{Sistemas prehistóricos de captación de agua}

En relación a los sistemas prehistóricos de captación de agua, se pueden documentar tanto en los poblados como en el campo diversos tipos: pozos, canalizaciones con cisternas y charcas o cubetas artificiales y naturales. Así, por ejemplo, una charca natural como es sa Bassa Verda (Ciutadella) depende totalmente del ciclo natural de lluvias para poder almacenar agua. A su lado se asentó una pequeña comunidad humana formando un poblado de navetas de habitación durante el II mileno ANE (Ferrer, 2010).

En cambio, en el Coll de Cala Morell (Ciutadella), una pequeña península donde también se documenta un poblado de navetas, la captación de agua se hizo a través de una balsa construida por sus habitantes. Tiene una forma irregular, está forrada de piedra de pequeño tamaño y su base está formada por una capa de arcilla limpia de impurezas de unos $70 \mathrm{~cm}$ de potencia. Esta arcilla impermeabilizante es la que permitía el mantenimiento del agua en su interior. De esta 


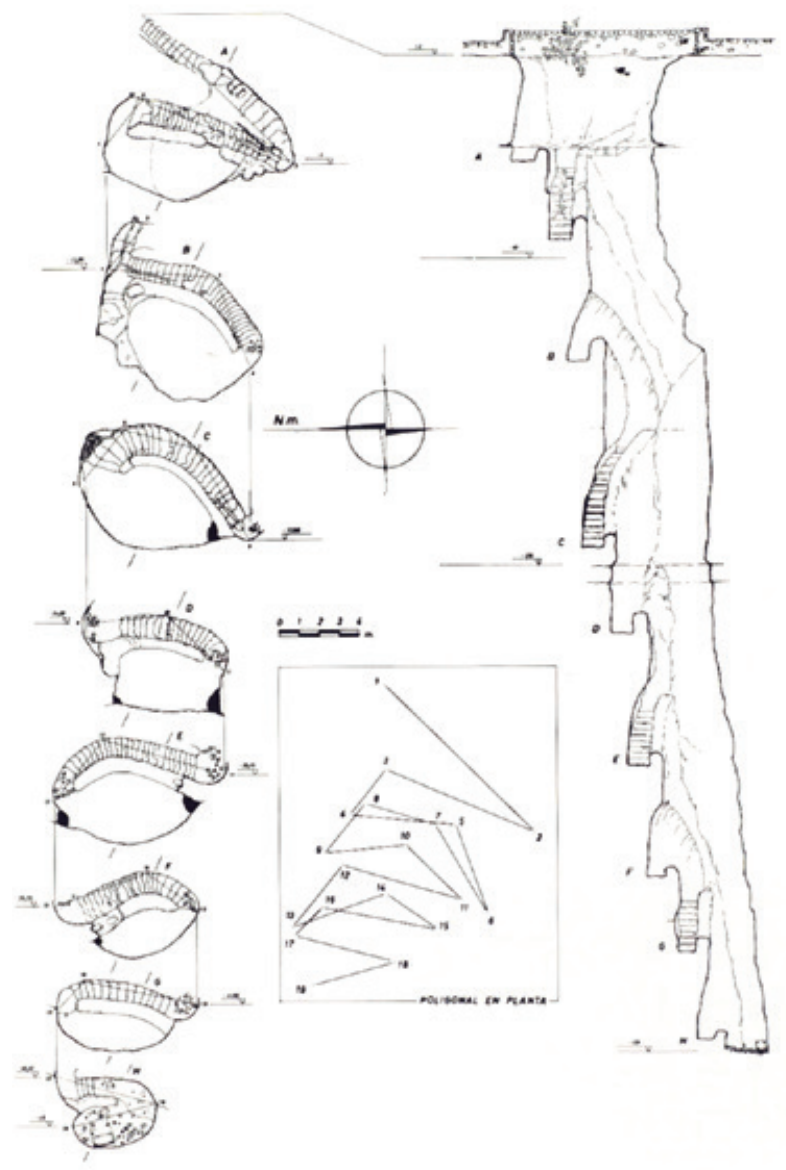

Figura 4. Planta y sección del pozo de na Patarrà, en el municipio de Alaior (según Trias, 1980).

Figure 4. Floor plan and section of the well of Na Patarra, in the municipality of Alaior (according to Trias, 1980).

balsa parece que sale una canalización que conectaría con otra un poco más al sur (en fase de excavación). La ocupación de este poblado se sitúa entre el 1.600 y el 1.200 ANE (Anglada et al., 2018).

Otro tipo de estructura que se documenta con cierta frecuencia en Menorca son los pozos. No hay una tipología clara en este tipo de estructuras, ya que seguramente su excavación y acondicionamiento dependerán de las condiciones locales del terreno. Pero hay ejemplos muy destacados, como son el de na Patarrà (Alaior), Binimaimut (Maó), Calescoves (Alaior), Macarelleta (Ciutadella) o Alcaidús (Alaior). El pozo de na Patarrà está cerca del poblado talayótico deTorralba d'en Salort, en la zona central de la isla y dentro de los terrenos miocenos. Para su excavación se habría aprovechado una diaclasa preexistente, donde el agua se acumulaba en cubetas excavadas por su recorrido. Así pues, se habría trabajado un acceso para facilitar que la gente pudiera subir el agua a la superficie, formada por nueve tramos de escalones. Tiene una profundidad de unos 47 metros y una anchura de unos 6 metros (Fig. 4) (Trias, 1980; Plantalamor, 1991).

El pozo de Calescoves está situado muy cerca del mar, en el interior de una pequeña península cerrada por una muralla. En esta zona no se ha documentado ninguna estructura de hábitat, pero el cierre junto a la existencia del pozo parece indicar que de alguna forma esta zona estuvo ocupada. Está excavado en la roca, bajando de forma inclinada en rampa con escalones. Tiene unos $10 \mathrm{~m}$ de profundidad y una anchura de entorno a 1,60 m (Plantalamor, 1991).

Las cisternas excavadas en la roca son otro de los elementos destacados de la captación de agua en la prehistoria de la isla. Este tipo de construcciones hidráulicas está documentada principalmente en los poblados talayóticos y, la gran mayoría de ellas, en relación directa con las casas. Se pueden documentar en diversos espacios del interior de la vivienda, con un claro predominio de las cisternas situadas en el patio central de la casa (Pons, 2016). También, se han documentado en la zona exterior de las viviendas, delante de su fachada. La mayoría de estas cisternas son de sección piriforme. El cuello es estrecho y se abre formando un depósito globular de base plana. Hay ejemplos en diversas casas del poblado de Torre d'en Galmés (Alaior).

Pero también se documenta el reaprovechamiento de estructuras de épocas anteriores que ya han perdido su uso original y en época talayótica se utilizan con esta función de almacenamiento de agua. Muchas veces, por su tipología, se corresponden con algún tipo de hipogeo de enterramiento de la cultura pretalayótica, que ha sido vaciado y reutilizado para esta nueva función. Para los talayóticos es muy útil, porque de esta forma ya tienen el trabajo hecho y no tienen que excavar la roca, solamente sanear la estructura. Los ejemplos de esta reutilización de hipogeos son numerosos: hay en Torre d'en Galmés (Alaior) (Rosselló, 1984 y 1986; Plantalamor, 1991), Biniparratx Petit (Sant Lluís) (Guerrero et al., 2007) y en So na Caçana (Alaior) (Plantalamor, 1991)

Estas cisternas o cuevas reutilizadas pueden captar el agua a través de espacios preparados, como pueden ser los patios de las casas. El suelo natural está rebajado y nivelado formando una ligera pendiente que puede conducir el agua hacia el depósito, tanto si se encuentra en el interior de la casa como en su exterior. Incluso, en algunos casos se han documentado canalizaciones para el agua. En los yacimientos de Trepucó (Maó), Biniparratx Petit (Sant Lluís) y Sant Vicenç d'Alcaidús (Alaior) se han documentado casas que tienen canales excavados en la 


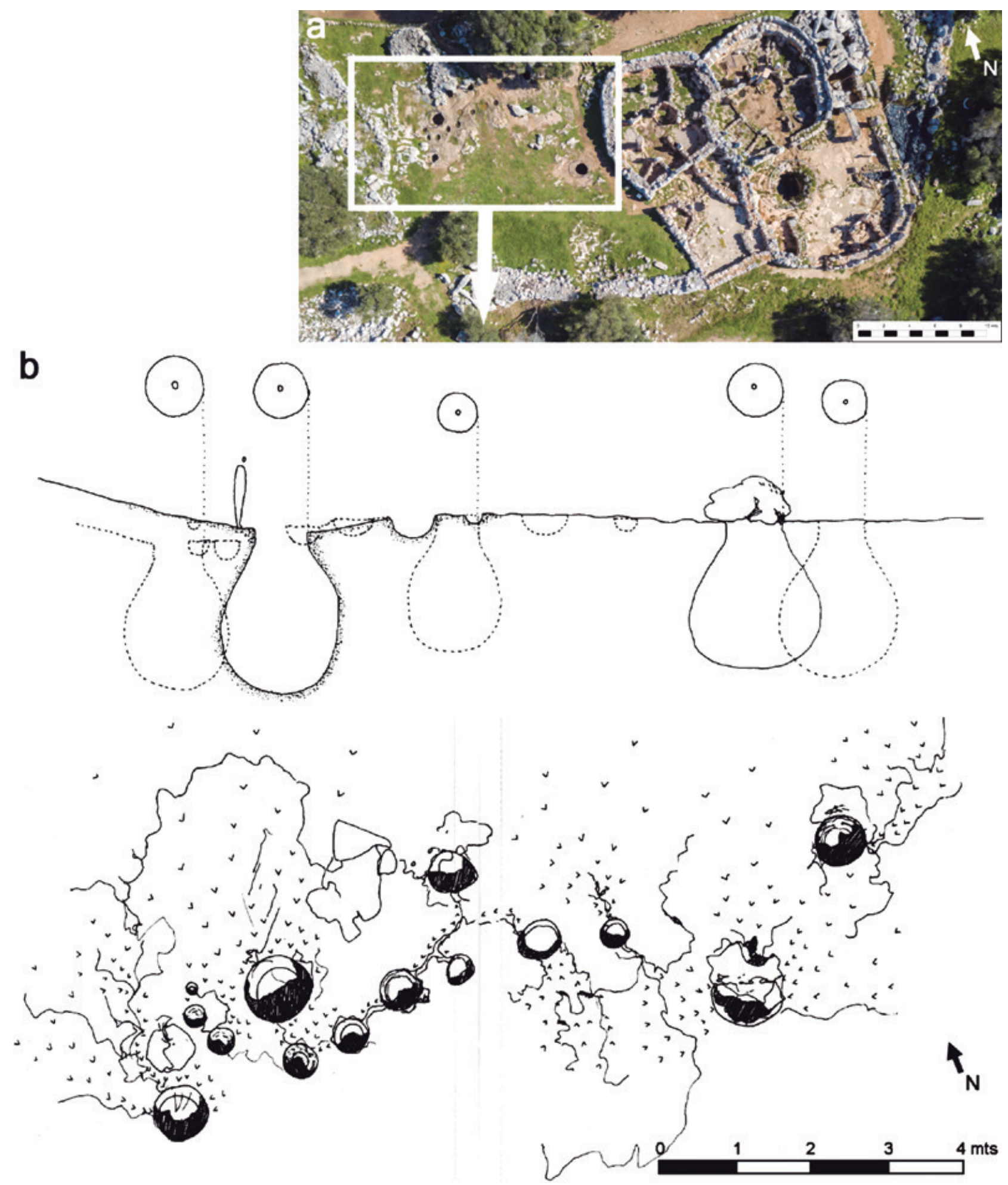

Figura 5. (a) Localización del sistema de captación de aguas del poblado deTorre d'en Galmés en Alaior (Amics del Museu de Menorca). (b) Planta y sección (según Vizoso y Cardona, 2009).

Figure 5. (a) Location of water collection system in the settlement of Torre d'en Galmés in Alaior (Amics del Museu de Menorca). (b) Floor plan and section (according to Vizoso and Cardona, 2009). 

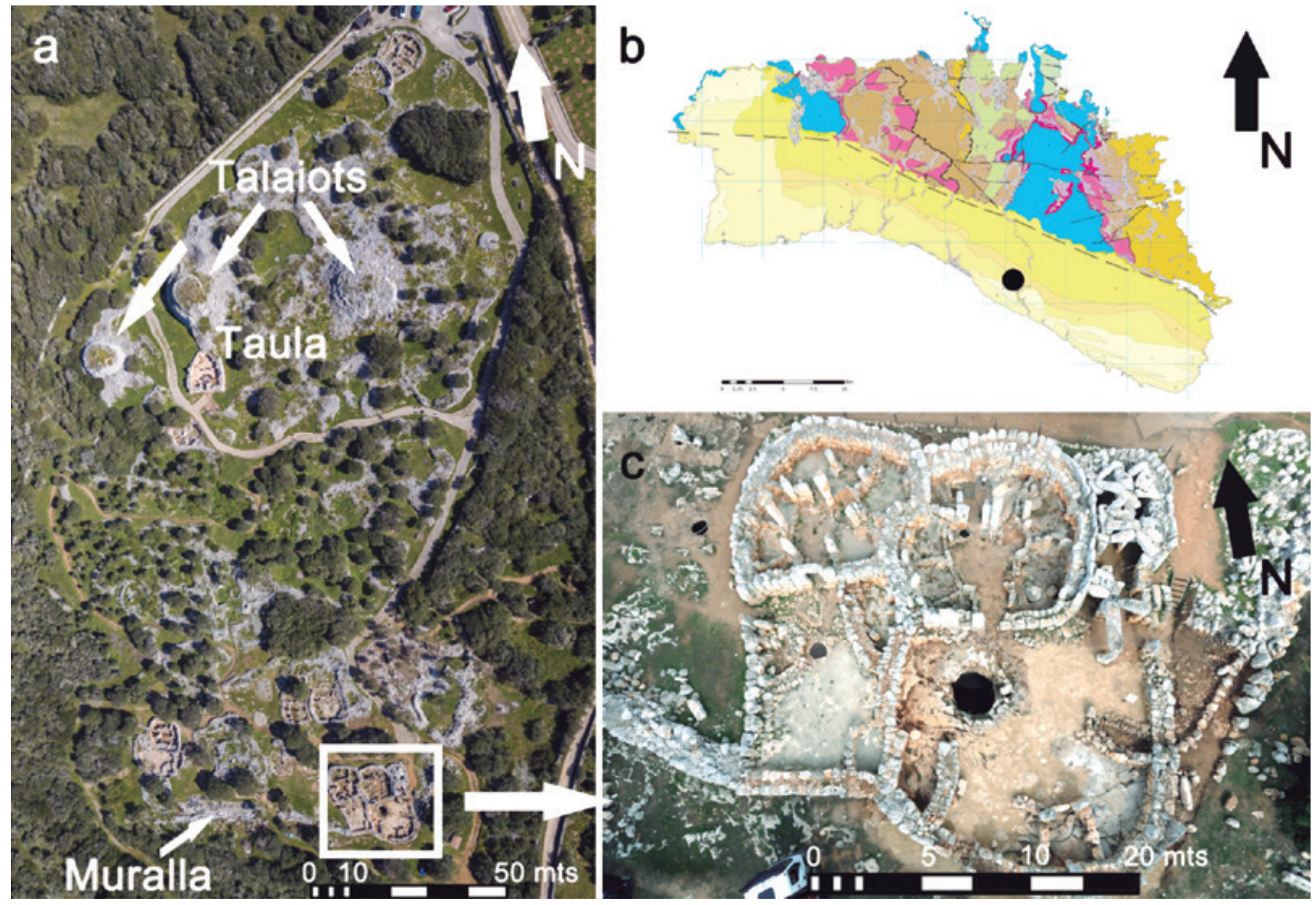

Figura 6. (a) Vista aérea del poblado deTorre d'en Galmés (Amics del Museu de Menorca). (b) Localización del poblado en la zona sur de la isla (Instituto Geológico y Minero de España, 1992). (c) Foto aérea de los círculos 6 y 7 deTorre d'en Galmés (AMM).

Figure 6. (a) Aerial view of the settlement of Torre d'en Galmés (Amics del Museu de Menorca). (b) Location of the settlement on the southern part of the island (Instituto Geológico y Minero de España, 1992). (c) Aerial photo of the circles 6 and 7 houses in Torre d'en Galmés (AMM).

roca madre (Plantalamor, 1991; Guerrero et al., 2007). También tenemos un ejemplo de canalización fabricada en piedra, pero que está fuera de su posición original, en el círculo 7 de Torre d'en Galmés (Ferrer et al., 2011).

Para finalizar esta síntesis de las diferentes estructuras relacionadas con la captación del agua en la prehistoria de Menorca, tenemos que hacer mención a los sistemas de recogida de agua más complejos. Tenemos tres ejemplos en los yacimientos de Sant Agustí Vell (Es Migjorn Gran), Torelló (Maó) y Torre d'en Galmés (Alaior). Todos ellos están formados por diversos depósitos conectados por canalizaciones que permitirían la circulación de agua de un depósito a otro (Plantalamor, 1991).

El ejemplo más complejo corresponde al documentado en Torre d'en Galmés durante la campaña de excavación llevada a cabo en el año 1977. En él se documentaron tres depósitos de unos $2 \mathrm{~m}$ de profundi- dad por $2 \mathrm{~m}$ de anchura, una serie de cavidades de pequeñas dimensiones, entre los $0,43 \mathrm{~m}$ y los $0,70 \mathrm{~m}$ de profundidad, canalizaciones que van uniendo algunas cavidades y depósitos, y un hipogeo pretalayótico reutilizado como cisterna. De esta forma, el agua se podía ir decantando y depurando pasando de una cavidad a otra hasta acabar acumulada en algún depósito o en el hipogeo-aljibe (Fig. 5ab) (Casal, 1982; Rosselló, 1984). Durante la excavación se documentaron cantos rodados dentro de las cubetas de decantación, muy cementados por las sustancias cálcicas en suspensión (Rosselló, 1986). Estas piedras adheridas también podrían haber servido para sujetar algún tipo de rama o fibra vegetal que favorecería la decantación (Plantalamor, 1991). Este sistema, localizado en la parte baja del poblado, podría responder a una preocupación comunal y serviría como zona de aprovisionamiento colectivo de todos los pobladores con independencia de las reservas domésticas. 


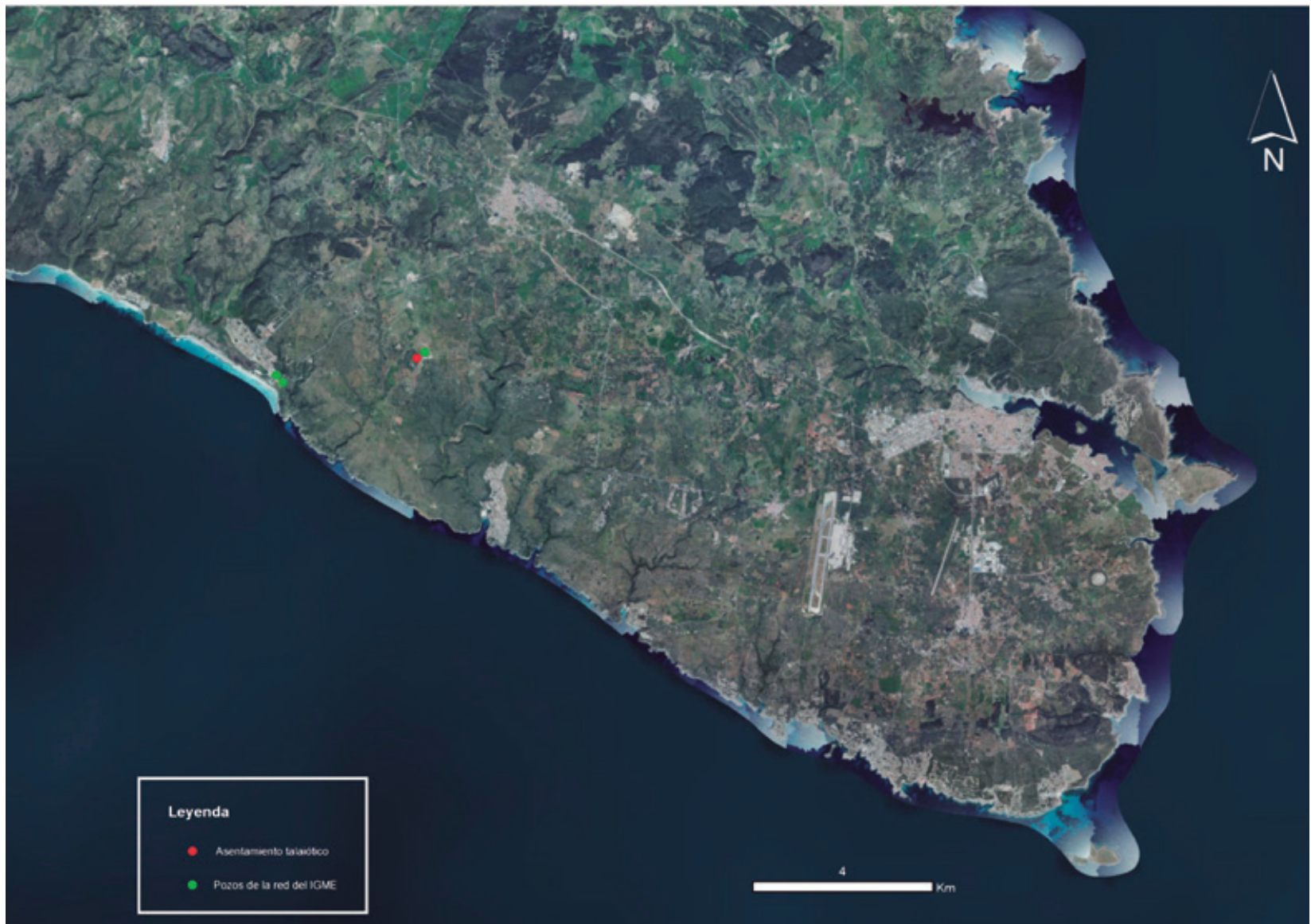

Figura 7. Yacimiento talayótico (punto rojo) y pozos de referencias en los que se han tomado los niveles piezométricos (puntos verdes). Figure 7. Talayotic settlement (red dot) and reference wells where piezometric level measurements were taken (green dots).
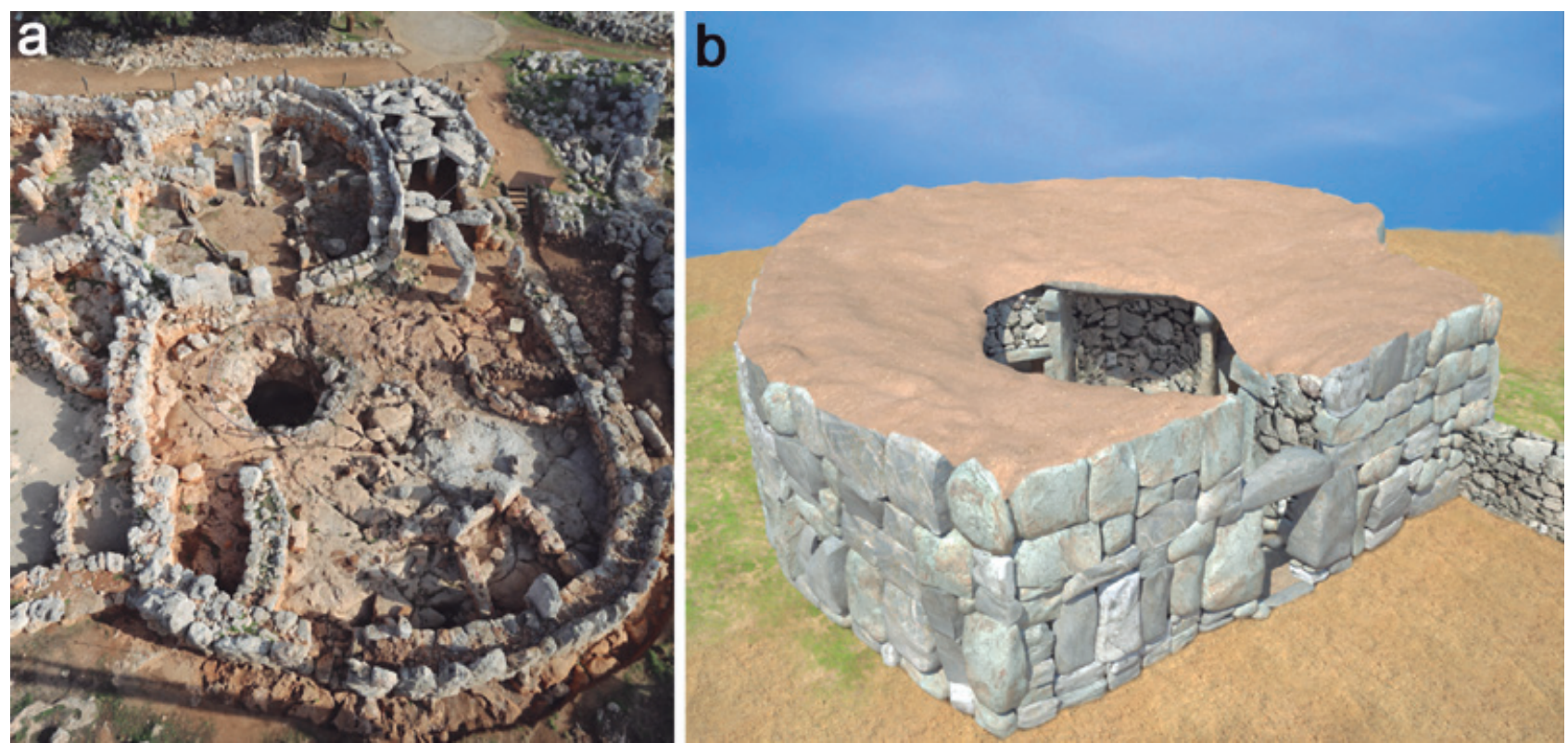

Figura 8. (a) Círculo 6, sala hipóstila y patio delantero, en el centro del patio se localiza la cisterna (AMM). (b) Reconstrucción 3D del Círculo 7 deTorre d'en Galmés (según Pons, 2016).

Figure 8. (a) Circle 6 house, hypostyle hall and front courtyard. The cistern is located in the middle of the courtyard (AMM). (b) 3D reconstruction of the Circle 7 house at Torre d'en Galmés (according to Pons, 2016). 


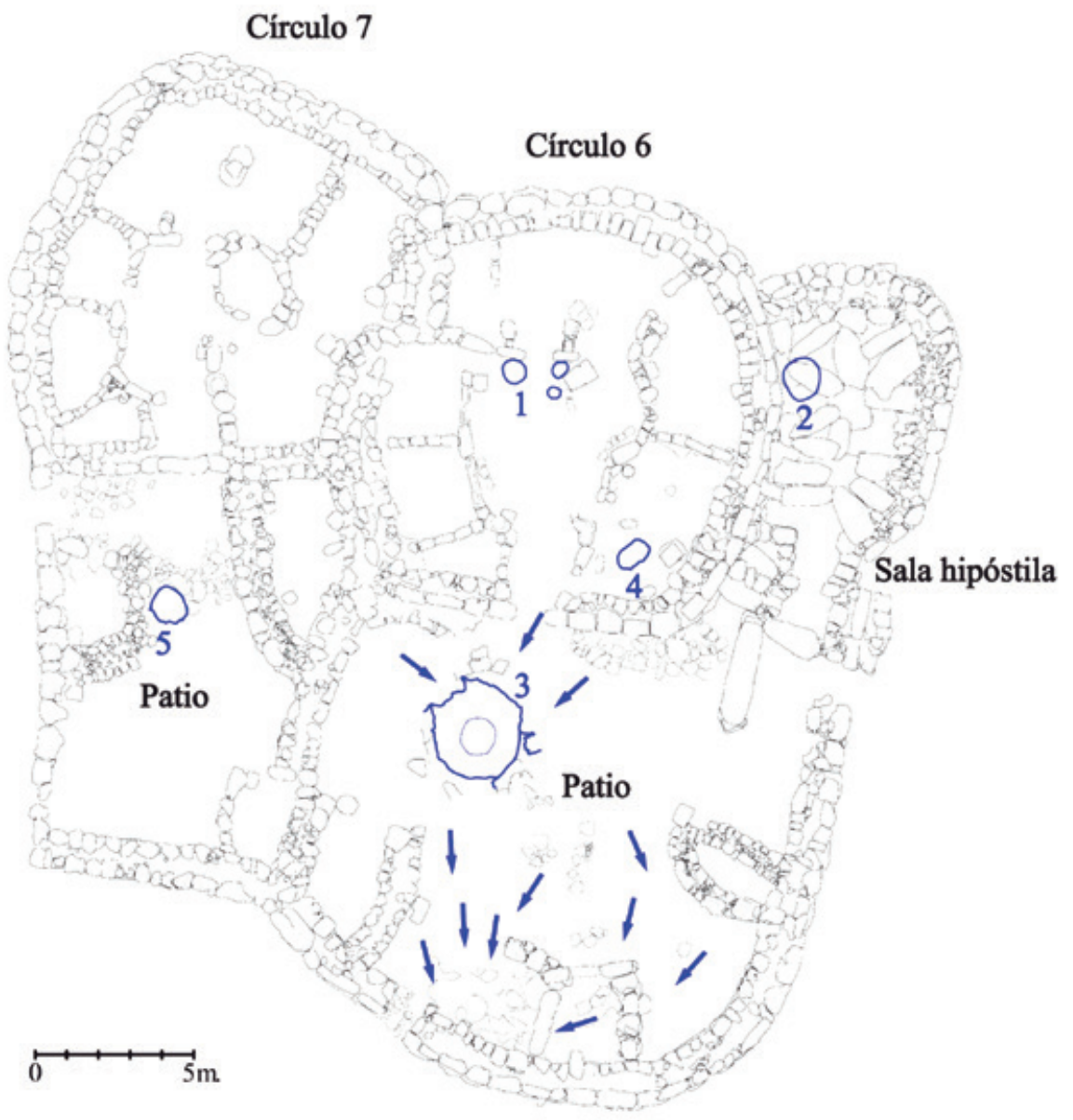

Figura 9. Planta general de los círculos 6 y 7 de Torre d'en Galmés con la localización de los elementos descritos en el texto: (1) cubetas artificiales de planta circular, (2) fosa o balsa que podría servir de desagüe, (3) cisterna del patio delantero, (4) depósito en excavación, (5) depósito del patio delantero del Círculo 7.

Figure 9. General floor plan of circles 6 and 7 houses at Torre d'en Galmés with the location of the elements described in the text: (1) circular floor plan artificial basins, (2) basin-shaped depression or pit which could have been used as drainage, (3) front courtyard cistern, (4) deposit under excavation, (5) front courtyard deposit at Circle 7 house.

\section{El poblado talayótico de Torre d'en Galmés}

Torre d'en Galmés es uno de los poblados más importantes de la cultura talayótica de Menorca. Se encuentra situado al sur del pueblo de Alaior, en la carretera que conduce hasta la playa de Son Bou. Está situado sobre un promontorio que tiene una altura de unos 100 m s.n.m. En la parte alta encontramos las estructuras más monumentales, los tres talayots. Junto al talayot central se encuentra el recinto de taula y las casas del poblado se localizan principalmente en la ladera sur. En la zona final del poblado es donde se sitúa el sistema de recogida de agua que acabamos de mencionar. El poblado está delimitado por lienzos de muros de discutible función poliorcética. En general, el desnivel acumulado entre la parte alta y la parte baja del poblado facilita el escurrimiento de las aguas superficiales hacia el sur (Fig. 6 a y b).

Desde el punto devista hidrogeológico, el yacimiento de Torre d'en Galmés se ubica en la Masa de Agua Subterránea de Es Migjorn (ES110MSBT1901M2) compuesta litológicamente por los materiales miocenos descritos, que constituyen un acuífero libre con contacto hidráulico en su margen sur con el mar (Fig. 1). Las cotas de los niveles piezométricos medidos en la red de pozos del IGME, presentan poca variación interanual. El pozo adyacente al poblado Torre d'en Galmés, tiene una cota piezométrica a 15 de mayo de 2019 de 79,82 m s.n.m. La cota de la superficie del terreno está a 110 m s.n.m. Este dato, indicaría que en la actualidad cualquier obra hidráulica de captación 


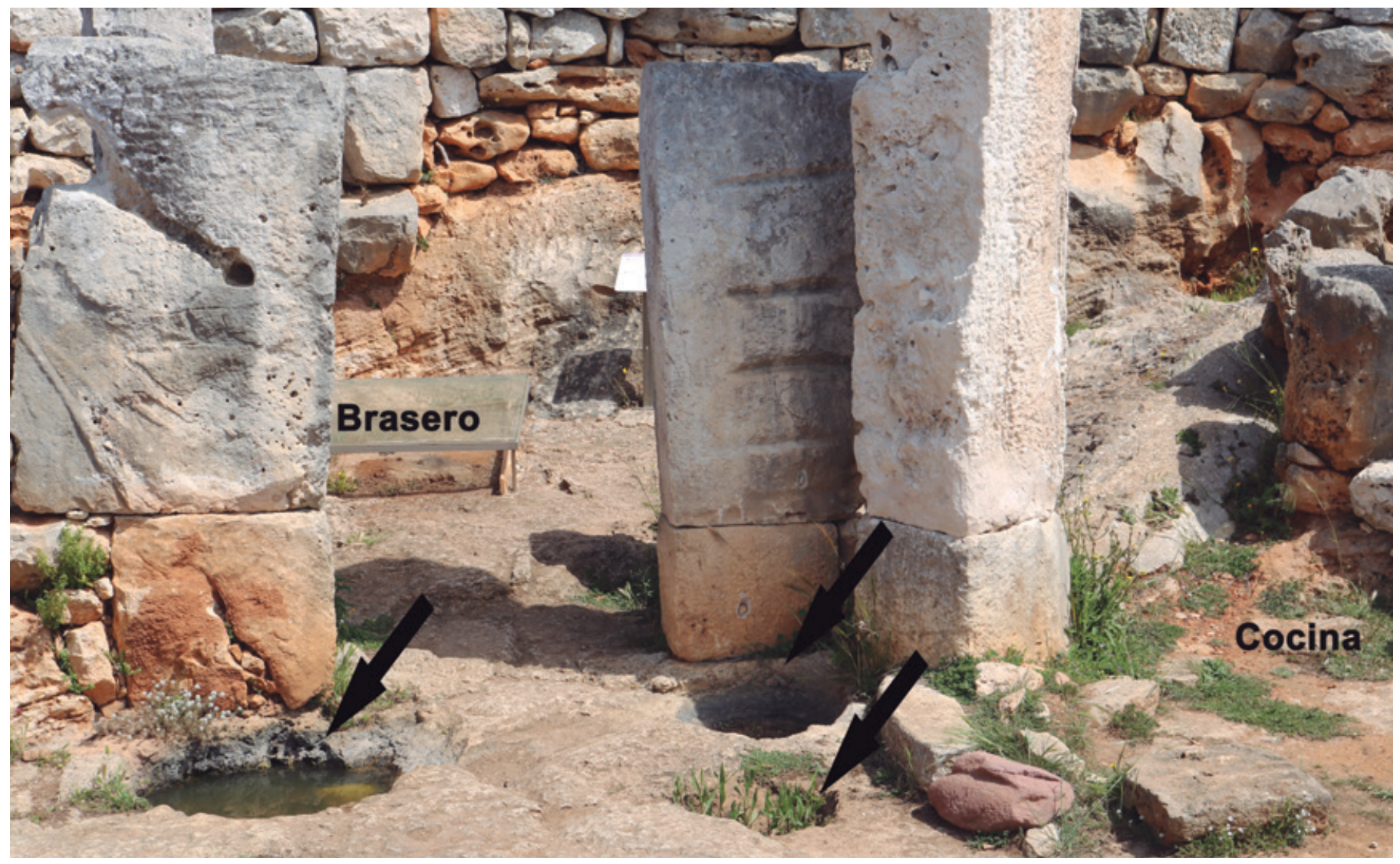

Figura 10. Serie de cubetas localizadas en el patio central del Círculo 6.

Figure 10. Series of basins located at the central courtyard of the Circle 6 house.

debería tener al menos $30 \mathrm{~m}$ de profundidad para llegar a la lámina de agua freática. Los pozos de la red del IGME al sur del poblado, cercanos a la playa de Son Bou, tienen una cota piezométrica en torno a 9,49 m s.n.m (Fig. 7), lo que indica en su relación con los pozos medidos en Torre d'en Galmés que la dirección del flujo del agua subterránea en este sector es prácticamente N-S.

Las casas excavadas en este poblado se corresponden con el patrón típico de la vivienda talayótica documentado en diversos poblados y descrito por diversos autores (Serra, 1961 y 1965; Rosselló, 1986, Plantalamor, 1991; de Nicolás, 1997; Hernández-Gasch, 2011; Ferrer et al., 2011; Pons, 2016). Se las denomina casas circulares o círculos de habitación, ya que su planta tiene tendencia circular. No se conocen casas de este tipo cuya construcción date más allá del siglo V ANE. El acceso a la vivienda se realiza desde el sur y las habitaciones se disponen de forma radial alrededor de un patio central que estaría a cielo abierto. En un par de casas de este poblado también se ha podido documentar una cisterna en la parte exterior de la vivienda, justo delante de la puerta de acceso y dentro de un gran patio exterior. Los círculos 6 y 7 están adosados, tienen una estructura interna muy similar y en la zona adyacente a su fachada se formaron unos patios exteriores de grandes dimensiones con diferentes espacios y estructuras, entre ellas, como acabamos de mencionar, una cisterna para la recogida de agua (Fig. 6c).

El círculo 6 corresponde a una típica casa talayótica de planta circular, aunque por su lado oeste el muro tiene un recorrido irregular, al compartirlo con el círculo 7. El muro que delimita la estructura es de doble paramento, con la cara exterior formada por un zócalo de piedras colocadas en posición horizontal y encima una hilera de bloques colocados en posición vertical (muchos de ellos están perdidos actualmente, principalmente los que forman la fachada). La cara interior está construida con piedras de pequeño y mediano tamaño y en su recorrido se han documentado tres pilares polilíticos insertos en el muro para darle una mayor estabilidad.

Los muros que dividen el espacio interior son de paramento simple, construidos con bloques de pie- 

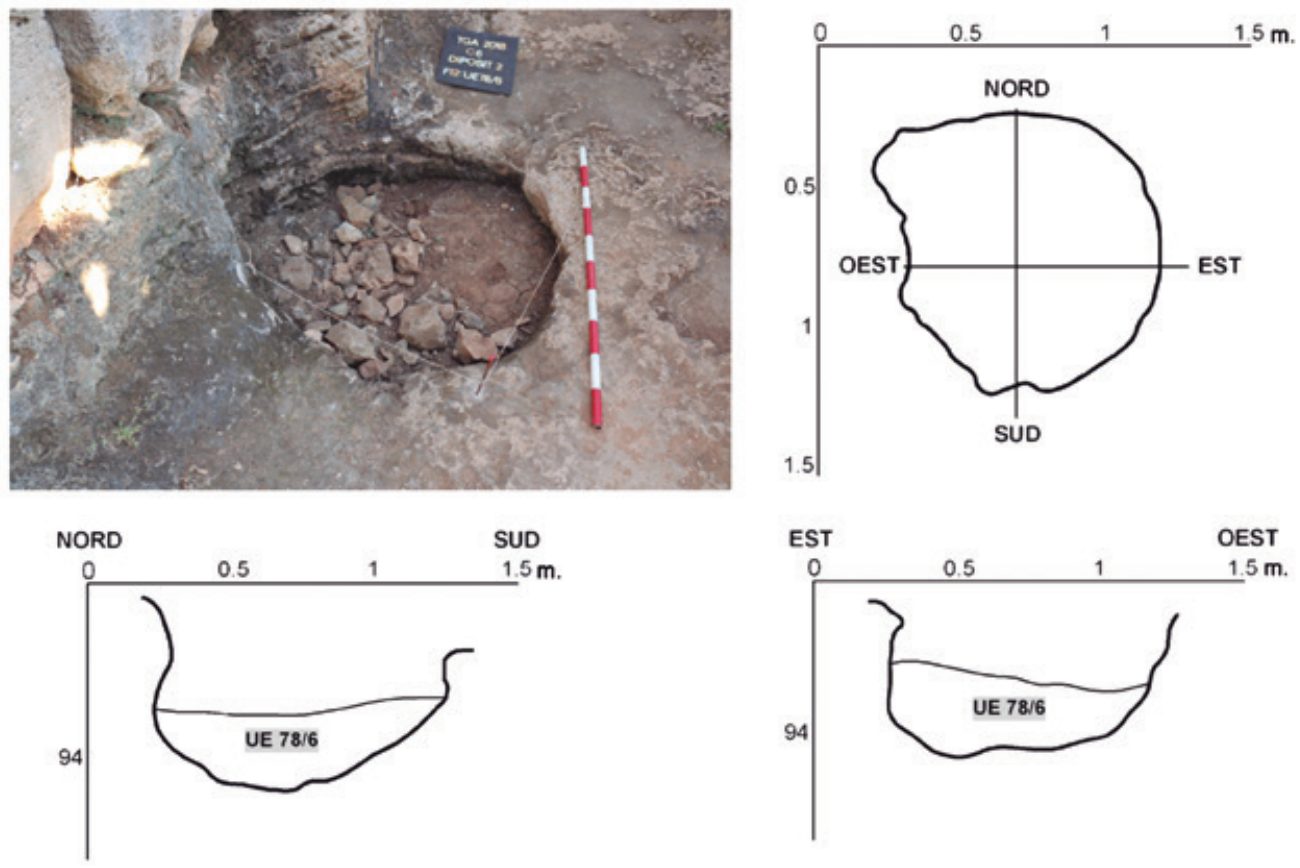

Figura 11. Balsa en el interior de la sala hipóstila adosada al Círculo 6.

Figure 11. Pit located inside the hypostyle hall attached to the Circle 6 house.
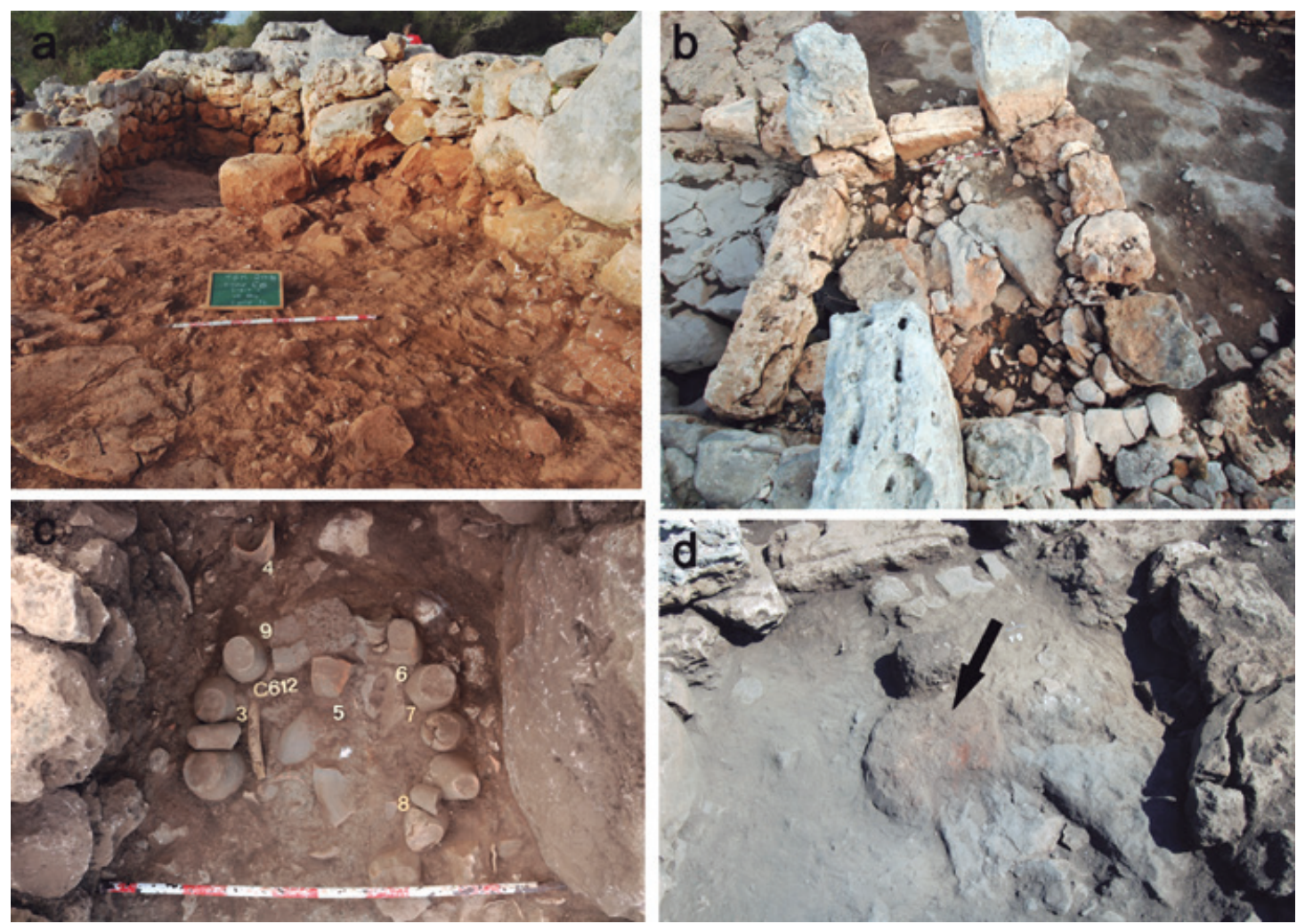

Figura 12. Excavación de diversos ámbitos del patio delantero del círculo 6: (a) niveles arcillosos de los ámbitos 1 y 2, que podrían estar cubiertos y pavimentados. (b) El ámbito 3, dispone de una canalización este-oeste cubierta con tres grandes losas. (c) Posible estructura de combustión hallada en el ámbito 4. (d) Base de barro hallada en el ámbito 3.

Figure 12. Excavation of several areas in the front courtyard of the circle 6 house. (a) Mud levels in areas 1 and 2 , which could have been covered and paved. (b) Area 3, with an east west canalization covered with three large stone slabs. (c) Possible combustion structure found in area 4. (d) Clay base found in area 3. 

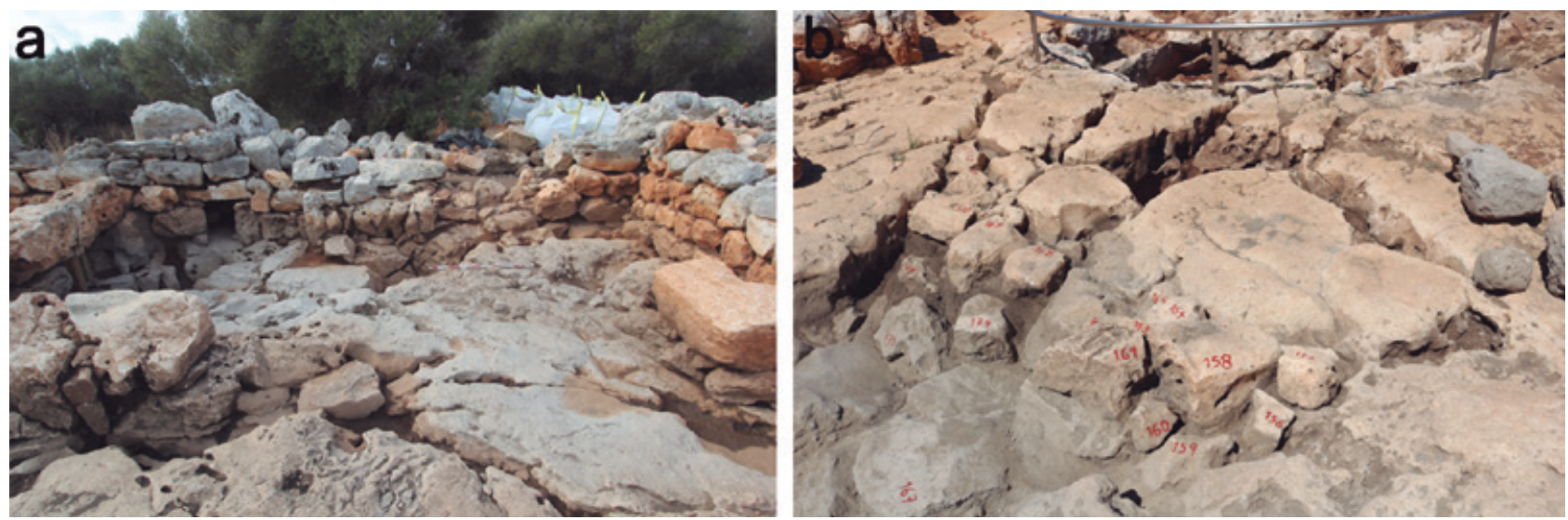

Figura 13. (a) Zona marginal del patio en el extremo sur-oeste, donde todavía hoy se forma una charca; también se observa una apertura que podría funcionar como desagüe. (b) Pavimentación con arcillas y piedras encastadas alrededor de la cisterna.

Figure 13. (a) Marginal area at the south-western end of the courtyard, where water still continues to accumulate nowadays; an opening which could function as drainage can be seen. (b) Earthen floor and stone pavement around the cistern.

dra. Las puertas que dan acceso a las habitaciones del lado oeste están formadas con bloques de piedra en el umbral y las jambas, que tienen un rebaje, seguramente para instalar algún elemento de cierre de estos espacios. La zona este está más degradada, aunque se conservan dos habitaciones. En la zona norte se documentó un gran espacio destinado al descanso de los habitantes de la casa, con un lecho construido en la misma roca madre y una placa de arcilla a su lado que habría hecho la función de brasero para mantener caliente la habitación durante el invierno (Lara, 2011). Posiblemente estas habitaciones estarían cubiertas con un techo formado por vigas de madera, ramaje y arcilla (Figs. 8ab y 9) (Pons, 2016).

Por lo que respecta al patio central, estaba delimitado por 6 columnas monolíticas. De 5 de ellas sólo se conserva la base. La sexta columna se ha podido restituir en su sitio original, incluso con el capitel que la coronaba. En el ángulo NE de este patio se ha documentado el hogar de la casa, siguiendo el mismo patrón que vemos en las otras casas talayóticas excavadas en la isla. Excavados en el piso del patio y del ámbito SE se observan una serie de 5 cubetas artificiales (Fig. 9, $\mathrm{n}^{\circ} 1$ ) de planta circular y de distintas medidas, entre $0,72 \mathrm{~m}$ y $0,34 \mathrm{~m}$ de ancho $x 0,34$ y $0,20 \mathrm{~cm}$ de profundidad. Atendiendo a su localización, en el patio y cerca de la cocina, podrían tener gran variedad de usos, aunque no se descarta la posibilidad de que también sirvieran para almacenar agua traída de otros depósitos de mayores dimensiones (Fig. 10). Cabe decir que se documentan este tipo de cubetas en otros círculos del mismo poblado. También dentro de la casa y en el ámbito SE, se halla un depósito en proceso de excavación que, en este caso, al estar ubicado en un espacio teóricamente cubierto por techumbre, podría ser algún tipo de silo de almacenaje (Figs. 9, $\mathrm{n}^{\circ} 4$ ).

Adosada por su lado este hay un recinto cubierto o sala hipóstila. Se trata de una estructura anexa cuya función es desconocida hasta el momento porque se han realizado pocas intervenciones en este tipo de edificios a la par que se han obtenido pocos datos. Atendiendo a niveles de cenizas y granos carbonizados recuperados en niveles del siglo I ANE en el conjunto Cartailhac, es posible que se tratara de un espacio de almacenaje (Sintes y Isbert, 2008). La parte norte de la sala hipóstila del círculo 6 fue excavada en 1943 y durante su excavación se documentaron materiales del periodo talayótico, romano e islámico (siglos X-XIII). La parte sur de la misma fue objeto de una intervención de excavación, restauración y adecuación en 2004. La sala hipóstila del círculo 6 destaca por sus dimensiones; el espacio se distribuye en dos naves separadas por una hilera de columnas de tipo mediterráneo, formada porvarios tambores que son más estrechos en la base y más anchos en la parte superior. La cubierta del edificio en este caso es de piedra y se ha conservado una parte importante de la misma. En el interior, excavada en el piso, hay una fosa o balsa de $0,60 \mathrm{~m} \times 0,60 \mathrm{~m} \times 0,50 \mathrm{~m}$ que podría cumplir una función de depósito de agua o silo. Tal vez, teniendo en cuenta la inclinación del suelo, podría acumular agua procedente del exterior, ya sea de posibles filtraciones o de la misma entrada al recinto (Figs. $9, n^{\circ} 2$ y 11 ).

Cercando la fachada de la casa y la sala hipóstila mediante muros enlazados de doble paramento se incorpora un patio exterior o delantero. Se accede al conjunto a través de un portal lateral al este, de carácter monumental, con un corredor dintelado y que dis- 


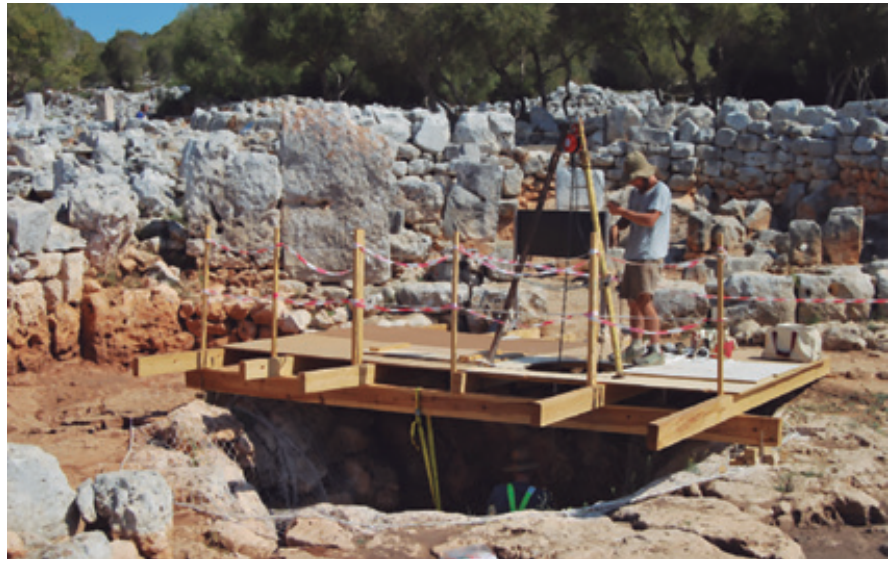

Figura 14. Plataforma de madera instalada para llevar a cabo la excavación de la cisterna.

Figure 14. Wooden platform erected to carry out excavation of cistern.

curre en paralelo a la entrada de la sala hipóstila hasta dar acceso a la casa circular. El patio, de unos 135,98 $\mathrm{m}^{2}$ útiles, es un espacio a cielo abierto alrededor del cual se construyen ámbitos aprovechando los ángulos que permite el muro perimetral. Se han documentado cuatro ámbitos y una cisterna. En los ámbitos se han documentado distintas deposiciones de carácter antrópico: una pequeña base de barro cocido, cenizas y restos de una masa compacta con material constructivo requemado como en el ámbito 3; niveles arcillosos en los ámbitos 1 y 2 y una interesante estructura de barro en el ámbito 4 (Fig. 12abc) (Corral et al., 2020). Desde el punto de vista cronológico, las tipologías cerámicas y relaciones estratigráficas documentadas marcan dos etapas diferenciadas: construcción y primer hábitat entre los siglos IV y III ANE, sobre la roca madre; y a partir de la segunda mitad del II ANE o inicios del I ANE, una nueva ocupación del espacio que comportará algunas reformas (y nuevos procesos de sedimentación de carácter antrópico sobre la roca madre) que se prolonga hasta el siglo II de nuestra era.

El piso rocoso donde se asienta el patio presenta un desnivel norte-sur de aproximadamente unos 0,50 $\mathrm{m}$. La cota más baja es en el extremo sur-oeste del espacio central, donde también se observan recortes de carácter antrópico resultado de la extracción de bloques conformando una especie de balsa. En consecuencia, incluso en la actualidad, el agua pluvial que circula por el piso del patio tiende a acumularse en dicho extremo. Además, en este extremo, el muro perimetral presenta una pequeña apertura que desaguaría cuando el nivel del agua fuese superior a la balsa (Fig. 13a). A través del estudio micromorfológico detallado de los sedimentos que amortizaban el

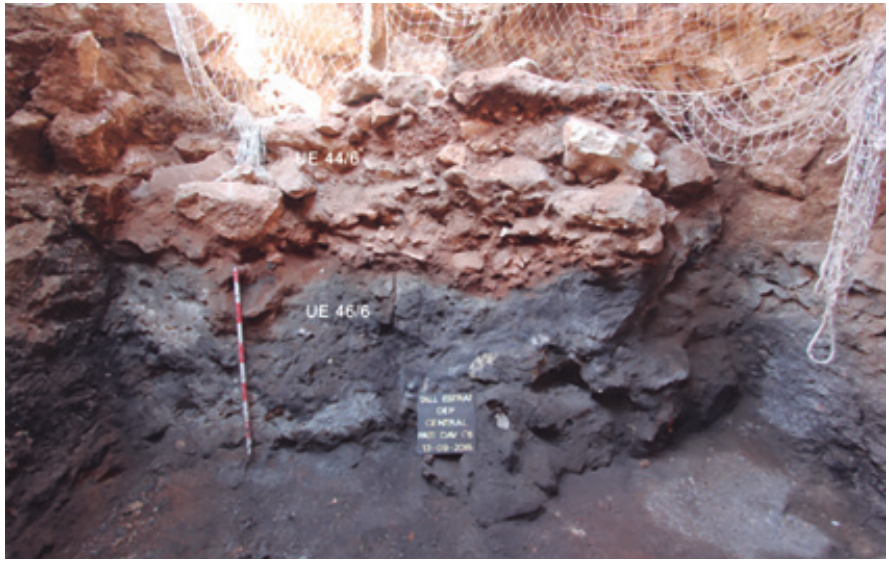

Figura 15. Sección norte-este en el interior de la cisterna; se observa un nivel de combustión de $1 \mathrm{~m}$.

Figure 15. North-east vertical section inside the cistern. One-meter combustion layer has been observed.

sector, se ha documentado la presencia de elementos antrópicos (carbones, huesos, cerámicas, etc.), mezclados con estiércol de herbívoro y caliza fosfatizada, todo ello pisoteado y bioturbado. Estos datos indicarían que la secuencia estratigráfica es el resultado de un proceso antrópico de deposición de elementos residuales y estabulación continuada de animales. Los materiales cerámicos hallados y la datación radiocarbónica de un hueso, parece indicar que este proceso

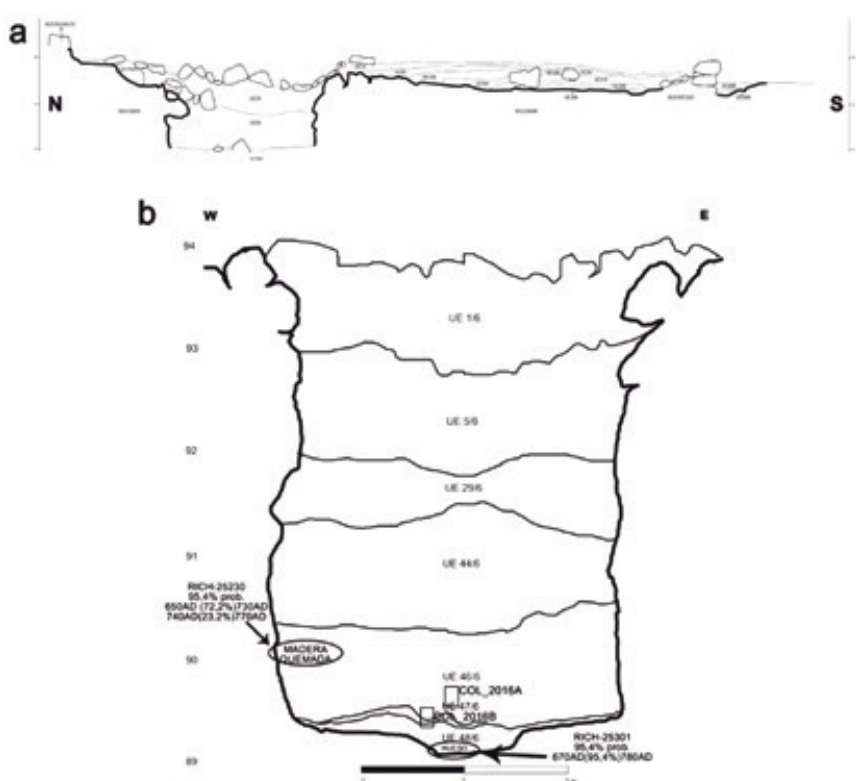

Figura 16. Sección de la cisterna y la localización de las distintas muestras tomadas.

Figure 16. Vertical section of cistern and location of the different samples taken. 


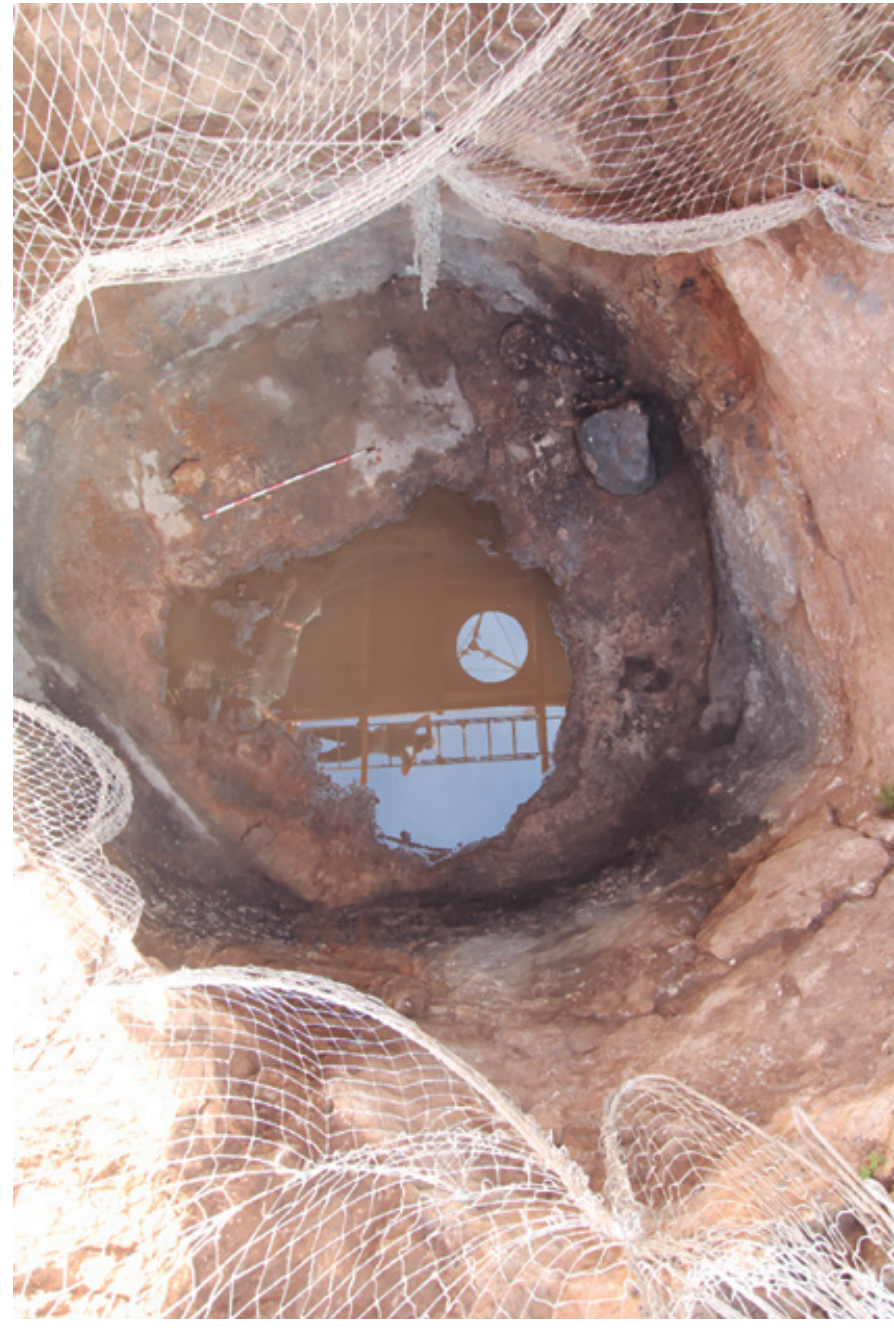

Figura 17. Balsa de decantación pocos días después de su excavación. Figure 17. Settling pool a few days after excavation.

comenzaría a finales de siglo II ANE. Con anterioridad a este siglo, esta zona del patio estaría habitada sobre roca madre, dando lugar a una zona encharcada (Corral et al., 2020).

El piso del patio, de roca caliza, presenta numerosas irregularidades que se salvan en los ámbitos y el sector central con arcillas rojizas, materiales de desecho y piedras encastadas. Este sistema de pavimentación es muy claro alrededor de la cisterna, situada en la parte alta (Fig. 13b).

\section{La cisterna del patio delantero del círculo 6}

En el contexto del proyecto de excavación del patio delantero del círculo 6, la excavación de la cisterna se llevó a cabo en la campaña de 2016 y ocupó más de un

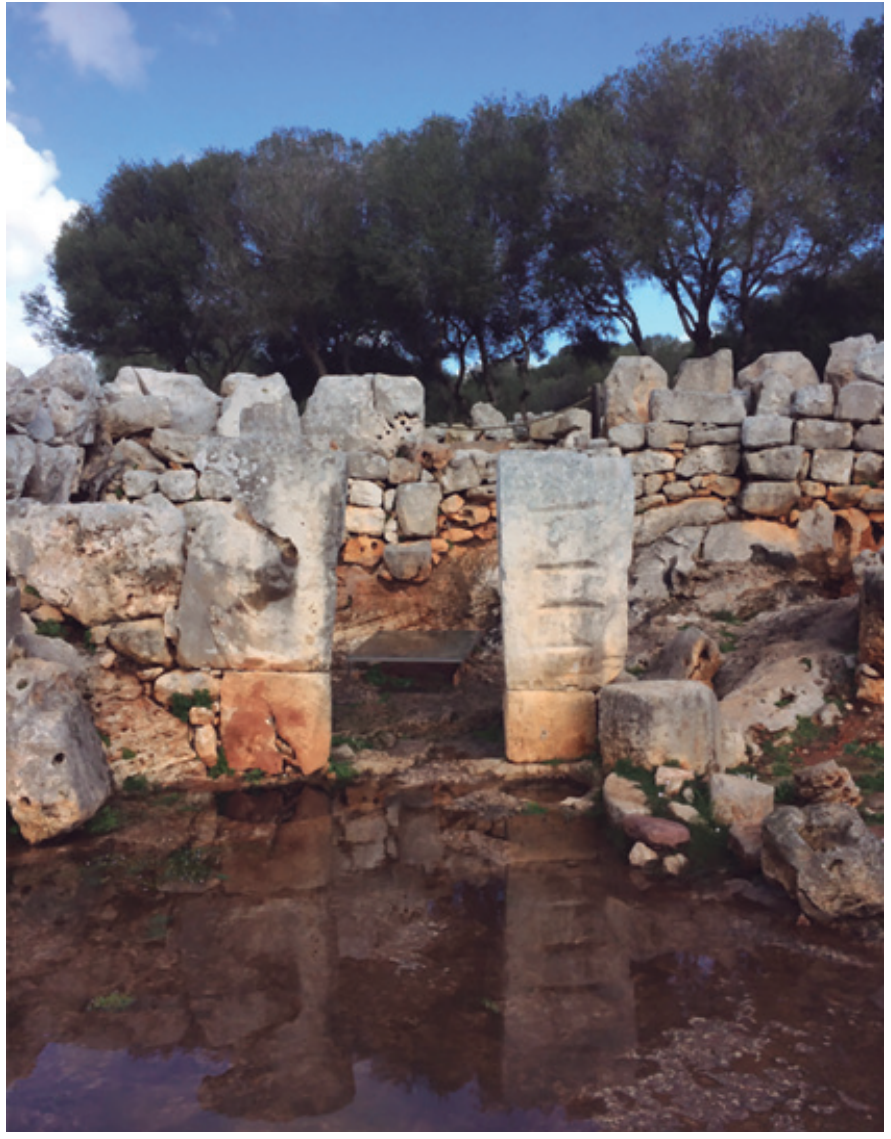

Figura 18. Cuando llueve se acumula agua en la superficie del patio central del círculo haciéndolo intransitable, cosa sorprendente en un patrón constructivo de más de 500 años (fotografía tomada en octubre de 2016).

Figure 18. Whenever it rains water accumulates on the central courtyard surface level of the house making it impassable. This is a surprising fact in a construction pattern more than five hundred years old (picture taken in October, 2016).

mes de trabajo de tres o incluso cuatro personas. Inicialmente se trataba de un hoyo excavado en la roca y amortizado con cantidades ingentes de piedra y sedimentos de carácter orgánico. Para poder llevar a cabo el vaciado de material de manera segura y eficaz, se decidió instalar una plataforma de madera con un orificio desde el cual, mediante la combinación de polea y polipasto, elevar las pesadas piedras y los capazos con sedimento (Fig. 14).

Las tres primeras unidades estratigráficas, hasta los 3,70 - $4 \mathrm{~m}$ de profundidad, se excavaron en extensión pues se trataba de niveles de amortización históricos con piedras y materiales talayóticos, púnicos, romanos, medievales y modernos. Las siguientes unidades se excavaron en sección, dejando un testimonio en el lado oeste con el objetivo de disponer de 

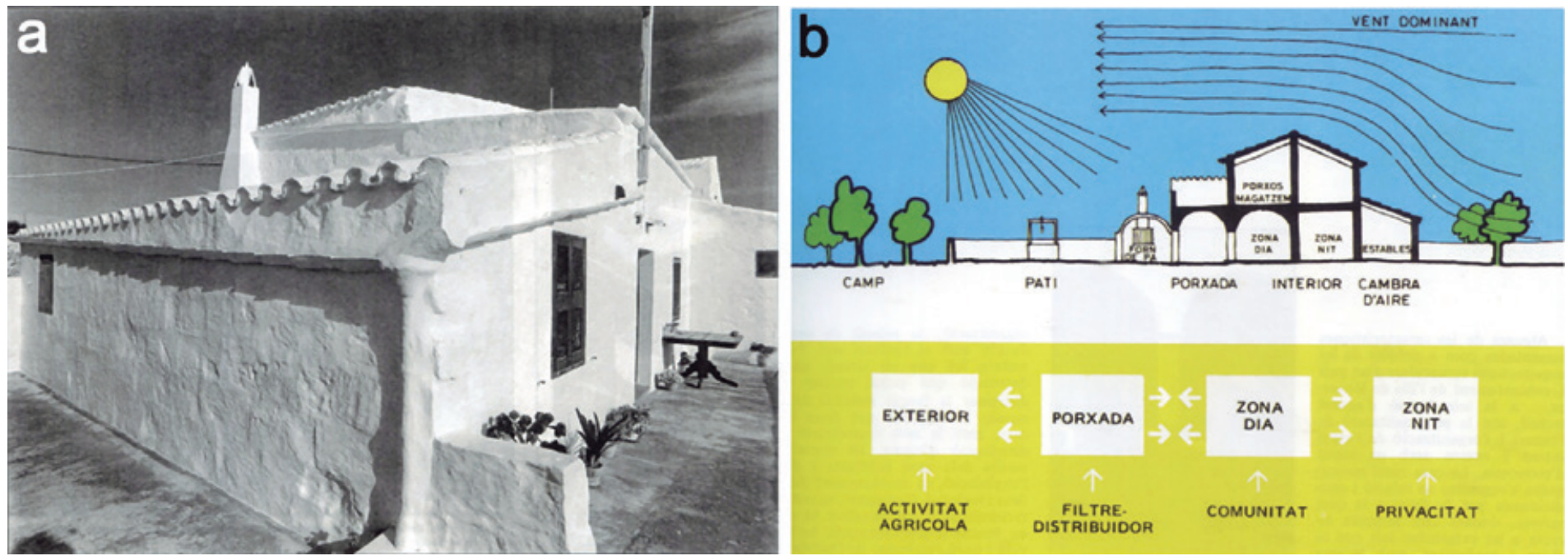

Figura 19. (a) Sistema de canalizaciones de agua del tejado en una casa rural menorquina de Sant Lluís. (Foto: Toni Vidal, en Jordi y Taltavull, 2017) (b) Esquema recurrente de casa rural menorquina. Es fácil encontrar similitudes con las casas y patios talayóticos (según Jordi y Taltavull, 2017).

Figure 19. (a) Rainwater harvesting system in a traditional farmhouse in Sant Lluís (Photo: Toni Vidal, in Jordi and Taltavull, 2017). (b) Recurring pattern in traditional Menorcan farmhouses. We can easily find similitudes with talayotic houses and courtyards (according to Jordi and Taltavull, 2017).
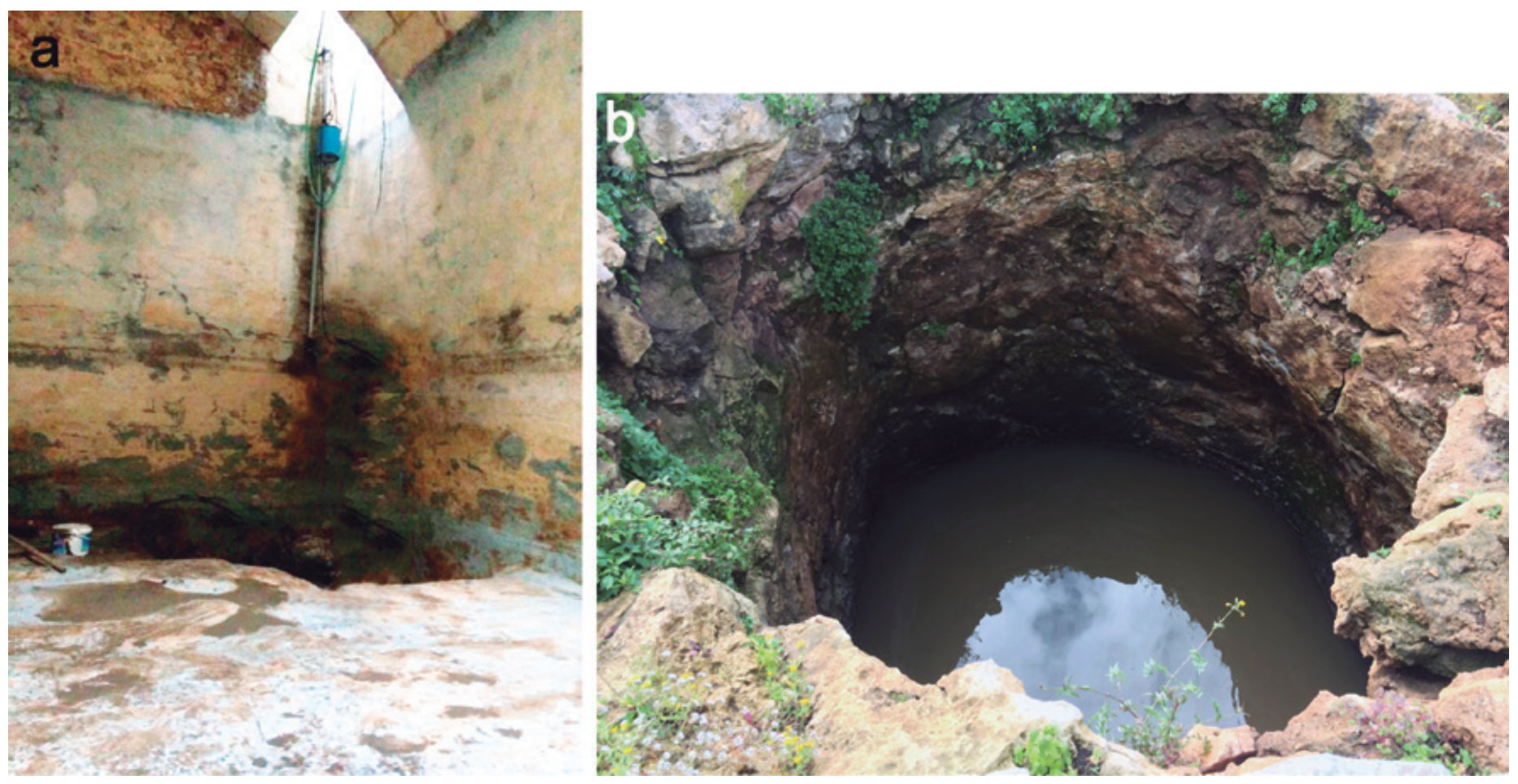

Figura 20. (a) Interior de una cisterna de una casa rural menorquina. En este caso está recubierta de una fina capa de cemento y cal.También dispone de una balsa de decantación. (b) Cisterna del círculo 6 deTorre d'en Galmés a pleno rendimiento en otoño de 2018.

Figure 20. (a) Inside a cistern in a traditional Menorcan farmhouse. In this case, the cistern is covered with a fine layer of cement and lime and also has a settling basin. (b) Cistern in the circle 6 house at Torre d'en Galmés fulfilling its original purpose in autumn 2018. 
una perspectiva nítida de la secuencia estratigráfica y tomar muestras para el análisis micromorfológico de los sedimentos. A los $4 \mathrm{~m}$ de profundidad se documentó un nivel negro, arcilloso, con piedra caliza más o menos calcinada y restos de madera quemada. Este estrato, de aproximadamente $1 \mathrm{~m}$ de potencia, indicó que se había llevado a cabo una importante combustión en el interior de la estructura (Fig. 15). Esto habría ocasionado el derrumbe de la cubierta y las paredes originales de la estructura, modificando considerablemente la morfología de su sección. EI análisis micromorfológico detallado de dos muestras en estos niveles de combustión, ha permitido sugerir que las cantidades de caliza calcinada o medio calcinada podrían estar relacionas con una producción de cal. Las dataciones radiocarbónicas realizadas hasta el momento, de un fragmento de madera carbonizado en la parte superior del nivel de combustión y de un hueso en la parte inferior, sitúan este episodio entre 650 - 780 de nuestra era (Fig. 16) (Corral et al., 2020).

Con todo, la estructura mide aproximadamente 3 $\mathrm{m}$ de ancho por 4,80 de profundidad. En su base, ligeramente convexa, se halló una balsa o depósito de planta circular y sección irregular, de $1 \mathrm{~m}$ de ancho por $0,40 \mathrm{~m}$ de profundidad aproximadamente, rellena de una delgada capa de arcilla roja anterior al episodio de combustión (Fig. 16). Dentro de este nivel de relleno se recuperaron dos fragmentos de ánfora romana que no van más allá del siglo I de nuestra era.

\section{Resultados e interpretación}

El hallazgo de una balsa recortada en el lecho parece indicar que se trata de una cisterna que deja de funcionar como tal cuando se abandona la casa alrededor del siglo I o II de nuestra era. La balsa, junto con la inclinación de la base ligeramente convexa, serviría para decantar mediante sedimentación de los elementos sólidos del agua. Desconocemos con exactitud la sección original de la estructura debido a su reutilización y amortización posterior. Seguramente este ejemplar, como tantos otros, seria de sección piriforme y con una boca de planta circular mucho más cerrada que la que presenta actualmente. Aunque es evidente que sus medidas han variado de manera significativa desde su uso como cisterna en la prehistoria, en la actualidad tiene una capacidad aproximada de unos $33 \mathrm{~m}^{3}$, es decir unos 33.000 litros.

Sin duda, una cuestión fundamental es la superficie de captación de agua. La falta de conclusiones definitivas sobre la disposición de la cubierta resulta problemática. Como se ha dicho, en otros conjuntos domésticos es usual encontrar cisternas frente a la casa, por ejemplo, en la casa 2 de Torelló d'en Sintes o la casa 1 del sector B de Biniparratx Petit. En este último caso, se interpreta la cisterna como una construcción previa a la casa (Hernández-Gasch, 2009). No se descarta esta posibilidad para el círculo 6. Actualmente, por su ubicación en el espacio, capta el agua acumulada en la mitad norte del patio delantero y podría captar de la cubierta del ámbito 2 del patio. Sin embargo, no llega a captar el agua que entra en el patio central de la casa por no haber ni inclinación norte-sur, ni ningún tipo de canalización. Este problema es más o menos recurrente en otros conjuntos domésticos del poblado, e implica que cuando hay importantes precipitaciones se acumule agua en dicha superficie haciéndola difícilmente transitable, cosa poco común y sorprendente en un patrón constructivo de casa con más de 500 años de uso (Fig. 18). En definitiva, todavía faltan datos al respecto de la disposición de la cubierta o del piso rocoso en la prehistoria. En la arquitectura vernácula rural es muy característico el aprovechamiento de los tejados de teja árabe para captar el agua de lluvia, obrando complejos sistemas de canalización y desagüe hasta cisternas adosadas o muy próximas a la vivienda. Las canalizaciones tienen gran protagonismo visual en el alzado de las construcciones (Fig. 19 a y b) (Jordi et al., 2017).

Otro aspecto de interés es si la estructura estuvo o no impermeabilizada. No se ha documentado capa de barro o mortero alguna. Es lógico que los episodios posteriores, su posible reutilización como calera, afectara gravemente un posible recubrimiento de las paredes. Cabe decir que hasta el momento en el mundo talayótico no se ha documentado ningún tipo de recubrimiento. Sí son conocidas en Menorca los depósitos y cisternas de opus caementicium y los recubrimientos de opus signinum para impermeabilizar. De vuelta a la arquitectura rural menorquina, siempre se revestían de un barro muy impermeable y, más adelante en el tiempo, con una capa rica de cemento (Fig. 20a) (Jordi et al., 2017).

La complejidad de este tipo de hábitats de la etapa final de la prehistoria de Menorca sugiere una consolidada organización social, donde cada unidad doméstica asume un considerable papel de autosuficiencia. La construcción de los patios delanteros delante de las casas circulares se puede entender como un eslabón más en este proceso, una expansión del espacio privado en detrimento del público y un aumento de la capacidad económica de estas unidades domésticas. En este contexto disponer de un sistema propio de abastecimiento de agua es fundamental. 


\section{Referencias}

Anglada, M.; León, Mª. J.; Ramis, D. and Salas, M. 2018. Es Coll de Cala Morell. Un jaciment obert al públic. Àmbit, 48, 24-27.

Casal i Fàbregues, J. 1982. Notes sobre una instal-lació prehistòrica de tractament primari d'aigua potable. Butlletí de la Societat Catalana de Ciències Físiques, Químiques i Matemàtiques. Vol. 2, n¹, 17-24.

Corral, B.; de Salort, C.; Carbonell, M. En prensa. Los patios exteriores de las casas circulares de la segunda Edad del Hierro de Menorca: los patios delanteros de Torre d'en Galmés. Congreso de Prehistoria y Protohistoria del Mediterráneo Occidental, Maó, 27-30 de abril de 2017. Consell Insular de Menorca y Universidad de Granada.

Corral, B.; de Salort, C.; Pérez-Juez, A.; Goldberg, P. and Van Strydonck, M. 2020. Nuevos datos sobre el patio delantero del Círculo 6 de Torre d'en Galmés (Alaior, Menorca): análisis micromorfológico de algunos suelos y dataciones C14. VIII Jornades d'Arqueologia de les IIles Balears, 147-158.

De Cet, M.; Lull, V.; Micó, R.; Rihuete, C. and Risch, R. 2017. Migration and integration during the Bronze and Iron Ages: the case of Menorca. In: Harald, H.; Daim, F.; Krause, J.; Risch, R. (Coord.), Migration and integration from Prehistory to the Middle Ages. Tagungen des Landmuseums für Vorgeschichte Halle (Saale), 145-167.

de Nicolás Mascaró, J. C. 1997. Casa prehistórica en el aeropuerto de Menorca. Aena Arte, 3. Madrid, 46-49.

Ferrer Rotger, A. 2010. Les basses temporals i I'home. Basses temporals mediterrànies. LIFE BASSES: gestió i conservació a Menorca. Institut Menorquí d’Estudis, 113122.

Ferrer Rotger, A.; Juan Benejam, G.; Lara Astiz, C. and Pons Machado, J. 2011. El jaciment de Torre d'en Galmés (Alaior, Menorca). Les intervencions d'Amics del Museu de Menorca: El Cercle 7. III Jornades d'Arqueologia de les Illes Balears, 2008. Llibres del Patrimoni Històric i Cultural, $\mathrm{n}^{\circ}$ 4. Consell Insular de Menorca, 109-117.

Giménez, J.; Gelabert, B. and Barón, A. 2004. Hidrologia subterrània del Migjorn. 2004. In: Fornós, J.; Obrador, A. and Rosselló, V. (eds.). Història Natural del Migjorn de Menorca. El medi físic i I'influx humà. Societat d'Història Natural de les Balears. Institut Menorquí d'Estudis. Fundació Sa Nostra, 121-128.

Guerrero, V.M.; Gornés, S.; Hernández, J.; de Nicolàs, J.; Morales, J.V.; Morales, A. and Pino, B. 2007. Avanç de les investigacions arqueològiques realitzades a l'assentament de Biniparratx Petit (Sant Lluís). L'arqueologia a Menorca: eina per al coneixement del passat, Llibres del Patrimoni Històric i Cultural, 3, Consell Insular de Menorca, 9-52.

Hernández-Gasch, J. 2011. Privatització i diversificació de I'espai domèstic en la societat balear de l'edat del ferro. III
Jornades d'Arqueologia de les Illes Balears, 2008. Llibres del Patrimoni Històric i Cultural, $\mathrm{n}^{\circ} 4$. Consell Insular de Menorca, 43-62.

Jansà i Clar, A. 2004. El clima del Migjorn. Fornós, J. J.; Obrador, A. and Rossolló, V. M. (eds.), Historia Natural del Migjorn de Menorca: el medi físic i l'influx humà. Societat d'Història Natural de les Balears, 39-52.

Jordi i Manent, V.; Taltavull i Femenias, E. 2017. Arquitectura Rural de Menorca. Publicacions de I'Enciclopèdia de Menorca. Fundació Enciclopèdia de Menorca.

Lara Astiz, C. 2011. Una estructura de combustió en el cercle Il de Torre d'en Galmés (Alaior-Menorca). III Jornades d'Arqueologia de les Illes Balears, 2008. Llibres del Patrimoni Històric i Cultural, $\mathrm{n}^{\circ}$ 4. Consell Insular de Menorca, 91-96.

Navarro Chueca, F. J. 2004. Excavaciones arqueológicas en el yacimiento "de Ses Talaies" de n'Alzina. Poblado talayótico afectado por las obras de la ronda Norte (Ciudadella) 2003. Col. Llibres del Patrimoni Històric i Cultural, 2. Consell Insular de Menorca 2004.

Obrador, A. 2010. Geología y estanques temporales. In: Fraga, P.; Estaún, I. and Cardona, E. (eds.), Estanques temporales mediterráneos. LIFE BASSES: gestión y conservación en Menorca. Col-lecció Recerca. Institut Menorquí d'Estudis, 15, 52-77.

Pérez-Juez, A. and Goldberg, P. 2018. Evidence of Quarrying at the Iron Age Site of Torre d'en Galmés, Menorca, Spain. Boletín Geológico y Minero, 129 (1/2): 353-370.

Plan Hidrológico de las Islas Baleares (PHIB). 2019. Aprobado por el consejo de Ministros según R.D. 701/2015, de 17 de julio, y revisión anticipada aprobada por el R.D. 51/2019, de 8 de febrero. Govern de les Illes Balears.

Plantalamor Massanet, LI. 1991. L'arquitectura prehistòrica $i$ protohistòrica de Menorca i el seu marc cultural.Treballs del Museu de Menorca, ${ }^{\circ}$ 12, Ed. Conselleria d'Educació i Cultura del Govern Balear. 627 pp.

Pons Machado, J. 2016. Caracterització de l'espai de l'hàbitat protohistòric de l'illa de Menorca: les cases de planta circular talaiòtiques. Tesis doctoral. $250 \mathrm{pp}$.

Tesis doctorals en xarxa (TDX), 28/03/2019, http://hdl.handle. net/10803/399295

Rosselló Bordoy, G. 1984. Excavaciones arqueológicas en Torre d'en Gaumés (Alayor, Menorca). El recinto de taula y el sistema de recogida de aguas (campañas 1974,1975 y 1977). Noticiario Arqueológico Hispánico, $\mathrm{n}^{\circ} 19, \mathrm{Ed}$. Ministerio de Cultura, 105-197.

Rosselló Bordoy, G. 1986. El poblado prehistórico de Torre d'en Gaumés (Alaior). Institut d'Estudis Baleàrics, Col. Monuments de les Illes Balears, 3. 91 pp.

Serra Belabre, Ma . L. 1961. De arqueología menorquina: círculos. Revista de Menorca, Ateneu de Maó, 65-74.

Serra Belabre, $M^{\mathrm{a}}$. L. 1965. Arquitectura ciclópea menorquina. Arquitectura megalítica y ciclópea Catalano-Balear, Ed. C.S.I.C., 151-172. 
Sintes, E. and Isbert, F. 2009. Investigación arqueológica y puesta en valor del recinto Cartailhac. Una unidad doméstica del s. II ANE en el poblado talayótico de Torre d'en Galmés. Patrimonio Cultural de España, $\mathrm{n}^{\circ} 1$, Ministerio de Cultura, 15-24.

Trias, M. 1980. Aportació a l'estudi de na Patarrà. Endins, $\mathrm{n}^{\circ} 7,63-67$.
Trilla i Arrufat, J. 1979. Hidrogeologia. In: Vidal Hernández (dir.), Enciclopèdia de Menorca. Geografia Física. Tom 1. Obra Cultural Balear de Menorca, 239-264.

Vizoso, F. and Cardona, J. 2009. Arquitectura de sa pluja a Menorca. Estudi de 52 exemplars de sistemes tradicionals de recollida superficial d'aigua. Trabajo Inédito.

Recibido: julio 2019

Revisado: noviembre 2019

Aceptado: enero 2020

Publicado: marzo 2021 